\title{
An Integrated Approach to Weather Radar Calibration and Monitoring Using Ground Clutter and Satellite Comparisons
}

\author{
Valentin Louf, ${ }^{\mathrm{a}}$ Alain Protat, ${ }^{\mathrm{b}}$ Robert A. WArren, ${ }^{\mathrm{a}}$ Scott M. Collis, ${ }^{\mathrm{c}}$ David B. WolfF, ${ }^{\mathrm{d}}$ \\ Surendra Raunyiar, ${ }^{\mathrm{b}}$ Christian Jakob, ${ }^{\mathrm{a}}$ AND WAlter A. Petersen ${ }^{\mathrm{e}}$ \\ ${ }^{\text {a }}$ School of Earth, Atmosphere and Environment, Monash University, Melbourne, Victoria, Australia \\ ${ }^{\mathrm{b}}$ Research and Development Branch, Bureau of Meteorology, Melbourne, Victoria, Australia \\ ${ }^{\mathrm{c}}$ Environmental Science Division, Argonne National Laboratory, Argonne, Illinois \\ ${ }^{\mathrm{d}}$ NASA Goddard Space Flight Center, Wallops Flight Facility, Wallops Island, Virginia \\ ${ }^{\mathrm{e}}$ NASA Marshall Space Flight Center, Earth Science Office, Huntsville, Alabama
}

(Manuscript received 17 January 2018, in final form 11 October 2018)

\begin{abstract}
The stability and accuracy of weather radar reflectivity calibration are imperative for quantitative applications, such as rainfall estimation, severe weather monitoring and nowcasting, and assimilation in numerical weather prediction models. Various radar calibration and monitoring techniques have been developed, but only recently have integrated approaches been proposed, that is, using different calibration techniques in combination. In this paper the following three techniques are used: 1) ground clutter monitoring, 2) comparisons with spaceborne radars, and 3) the self-consistency of polarimetric variables. These techniques are applied to a C-band polarimetric radar (CPOL) located in the Australian tropics since 1998. The ground clutter monitoring technique is applied to each radar volumetric scan and provides a means to reliably detect changes in calibration, relative to a baseline. It is remarkably stable to within a standard deviation of $0.1 \mathrm{~dB}$. To obtain an absolute calibration value, CPOL observations are compared to spaceborne radars on board TRMM and GPM using a volume-matching technique. Using an iterative procedure and stable calibration periods identified by the ground echoes technique, we improve the accuracy of this technique to about $1 \mathrm{~dB}$. Finally, we review the self-consistency technique and constrain its assumptions using results from the hybrid TRMM-GPM and ground echo technique. Small changes in the self-consistency parameterization can lead to $5 \mathrm{~dB}$ of variation in the reflectivity calibration. We find that the drop-shape model of Brandes et al. with a standard deviation of the canting angle of $12^{\circ}$ best matches our dataset.
\end{abstract}

\section{Introduction}

Radars are one of the most common and important instruments used in the atmospheric sciences. They work at high spatial $(\sim 1 \mathrm{~km})$ and high temporal resolution $(10 \mathrm{~min})$, providing four-dimensional information on the distribution of hydrometeors, precipitation intensity, and convective cloud dynamics. They are thus ideal tools for studying weather and climate processes, evaluating numerical simulations of precipitating cloud systems, and monitoring and nowcasting hazardous precipitation events. The C-band polarimetric radar $(\mathrm{CPOL})$, stationed near Darwin $\left(11^{\circ} \mathrm{S}, 131^{\circ} \mathrm{E}\right)$, northern Australia, since 1998, is an ideal tool for studying tropical convection (Keenan et al. 1998).

\footnotetext{
Corresponding author: Valentin Louf, valentin.louf@monash. edu
}

Yet, to be useful for these applications, it must be well calibrated.

The main quantity measured by radars is the radar reflectivity factor $Z_{m}(\mathrm{~dB} Z)$ :

$$
Z_{m}(r)=Z(r)+2 \int_{0}^{r} a(r) d r
$$

where $r(\mathrm{~km})$ is the radial distance, $Z(\mathrm{dBZ})$ is the nonattenuated reflectivity factor, and $a\left(\mathrm{~dB} \mathrm{~km}^{-1}\right)$ is the specific attenuation. The radar equation can be written in a simple form as (e.g., Probert-Jones 1962)

$$
Z_{m}=10 \log C+20 \log r+10 \log P_{r},
$$

where $P_{r}$ is the returned power by the target and $C$ is the so-called radar constant. The challenge of radar calibration is to estimate this constant $C$ for given radar settings and its variations in real time. It depends on a 
wide range of parameters, including wavelength, beamwidth, pulse length, transmitted power, and receiver gain. These quantities can vary over time as a result of degradation or maintenance of radar hardware. It is thus nearly impossible to estimate $C$ without using an external source of information.

CPOL, and all the radars of the Australian Bureau of Meteorology network, use a standard internal calibration procedure. However, these tests are performed at most a few times per year, with no rigorous calibration monitoring the rest of the time. As a result, while exploring the dataset we found 1) an abrupt change in radar calibration, 2) a long period of time where the radar is miscalibrated, and 3) large differences between radars with overlapping areas. It is for these reasons that we decided to find external ways to monitor the radar calibration, to be able to adjust the calibration quickly and accurately, and to have a common procedure for the entire operational network.

Over the years, many radar calibration techniques have been developed, using a fixed target (Atlas and Mossop 1960); collocated disdrometer data (Stout and Mueller 1968); solar interference (Whiton et al. 1976); high reflectivity gradients (Mueller 1977); ground clutter echoes (Rinehart 1978); or, for dual-polarization radar only, the self-consistency of polarimetric variables (Gorgucci et al. 1992). Joint observations of precipitating systems can also be used, by comparing with spaceborne radars (e.g., Anagnostou et al. 2001) or other surrounding radars (e.g., Vukovic et al. 2014). Radar calibration techniques are often evaluated separately. Yet, as proposed by Vaccarono et al. (2016), it is possible to retrieve additional information about calibration changes by combining different calibration techniques (the so-called integrated approaches).

In the present study we introduce an integrated approach called satellite and clutter absolute radar (SCAR) calibration to adjust the calibration of the reflectivity $Z_{h}$. We also introduce a broader framework for adjusting the calibration of the differential reflectivity $Z_{\mathrm{dr}}$. For $Z_{h}$, we use 1) ground clutter monitoring and 2) spaceborne radar comparison. Ground clutter monitoring is first used to adjust for calibration changes during periods of continuous operation. Comparisons with spaceborne radars are then used to determine the absolute calibration offset for each period. If satellite data are not available for a given place, or for a given season, then the self-consistency technique is used to provide an absolute value of calibration. For $Z_{\mathrm{dr}}$, we use the birdbath technique, that is, vertically pointing scans in light rain (Gorgucci et al. 1999).

Radar calibration monitoring using ground echoes was first introduced by Rinehart (1978), but it has been experiencing a renewed interest since the studies of
Silberstein et al. (2008), Marks et al. (2009), Melnikov and Zrnić (2015), and Wolff et al. (2015). It uses echoes from a multiplicity of ground targets close to the radar (generally within a $10-\mathrm{km}$ range) to determine a baseline value of clutter reflectivity that is used to monitor changes in calibration. This is called the relative calibration adjustment (RCA) technique. The RCA technique provides a value for each radar scan but monitors changes in calibration relative only to a baseline.

To get the reference value of that baseline, we compare the ground radar observations of precipitating systems against spaceborne radars, and the Tropical Rainfall Measuring Mission (TRMM) (Kummerow et al. 1998) and Global Precipitation Measurement (GPM) mission satellites (Hou et al. 2014). The cross validation of reflectivity from TRMM or GPM with ground radar reflectivity measurements has been the subject of numerous studies. It has been used to assess the quality of precipitation radar (PR) estimations (e.g., Schumacher and Houze 2000; Liao et al. 2001; Park et al. 2015), to study PR sensitivity (Heymsfield et al. 2000), to develop attenuation algorithms (Liao and Meneghini 2009), and to calibrate ground radars (Anagnostou et al. 2001; Wang and Wolff 2009). The approach followed here is the volume-matching method of Schwaller and Morris (2011) as modified by Warren et al. (2018).

We then take advantage of our long-term calibrated radar dataset to assess the performance of the selfconsistency technique (Gorgucci et al. 1992) and robustness to variations in the drop size distribution (DSD). A number of studies have used this method for radar calibration (e.g., Goddard et al. 1994; Scarchilli et al. 1996; Vivekanandan et al. 2003; Gourley et al. 2009). It uses the self-consistency, in light rain, of $Z_{h}, Z_{\mathrm{dr}}$, and specific differential phase $K_{\mathrm{dp}}$. The self-consistency technique allows for the estimation of one of these parameters given the other two. The principle of the technique is to estimate $Z_{h}, Z_{\mathrm{dr}}$, and $K_{\mathrm{dp}}$ from measurements of DSDs using disdrometer measurements, collected within the radar domain, and to perform scattering calculations using the transition ( $\mathrm{T}$ )-matrix formulation of Mishchenko et al. (1996). Importantly, T-matrix calculations require knowledge of some parameters that can vary over time (e.g., the temperature) or physical assumptions to be made regarding rain microphysics (e.g., the drop-shape model, the standard deviation of the canting angle). As will be shown later, assumptions in the drop-shape model and the canting angle are responsible for most of the variability of the self-consistency curves, and these variations can have an impact greater than $5 \mathrm{~dB}$ on the calibration of $Z_{h}$. We use our calibrated CPOL dataset as a reference to constrain these rain microphysics 
parameters and to assess the potential accuracy of the regionally tuned self-consistency technique.

This paper discusses development, adaptation, performance, and integration of these calibration techniques. Section 2 presents the instruments used in this study: CPOL, the nearby disdrometer, and the spaceborne radars on board TRMM and GPM. Section 3 describes the RCA technique, our new updates on the technique, and its results. Section 4 describes the TRMM and GPM comparison technique, and the iterative method we have developed to minimize the variations and improve its accuracy. In section 5 we review the self-consistency technique and its relevance for calibrating $Z_{h}$ and $Z_{\mathrm{dr}}$. Conclusions are given in section 6 .

\section{Instrumentation and data}

\section{a. Darwin C-band weather radar}

CPOL is a dual-polarization Doppler radar, working at a frequency of $5.6 \mathrm{GHz}$ with a pulse repetition frequency of $1000 \mathrm{~Hz}$ and a beamwidth of $1^{\circ}$. CPOL is located at Gunn Point $\left(-12.245^{\circ} \mathrm{N}, 131.045^{\circ} \mathrm{E}\right)$, about $25 \mathrm{~km}$ northeast of Darwin International Airport. CPOL performs a set of scans with an update time of $10 \mathrm{~min}$. This includes, nominally, a volume scan, a vertically pointing scan, and two RHI scans. The scan comprises 15 elevations: $0.5^{\circ}, 0.9^{\circ}, 1.3^{\circ}, 1.8^{\circ}, 2.4^{\circ}, 3.1^{\circ}, 4.2^{\circ}, 5.6^{\circ}, 7.4^{\circ}$, $10.0^{\circ}, 13.3^{\circ}, 17.9^{\circ}, 23.9^{\circ}, 32.0^{\circ}$, and $43.1^{\circ}$. An additional series of scans at $90^{\circ}$ is also performed regularly. The periodicity of the vertically pointing scan changes from season to season, and there are no such scans for seasons 2009/10 and 2010/11. The observed parameters are $Z_{h}$, $Z_{\mathrm{dr}}$, Doppler velocity $v$, differential phase $\phi_{\mathrm{dp}}$, spectrum width $\sigma_{v}$, and cross-correlation coefficient at zero lag $\rho_{\mathrm{hv}}$. The maximum unambiguous range of the volume scan is $140 \mathrm{~km}$ with a range gate spacing of $250 \mathrm{~m}$ and an azimuthal beam spacing of $1^{\circ}$. Between 2001 and 2007, to reduce the data size and to allow real-time transmission to the regional forecasting office, the radar gate range was changed to $300 \mathrm{~m}$, and data were sampled with an azimuthal resolution of $1.5^{\circ}$. Before 2007, the azimuthal indexing had to be corrected while, after 2007, the data are generated with the data synced to the azimuthal sampling. CPOL has produced more than 350000 plan position indicator scans over 17 wet seasons (November-May). Because of its location in the tropics and long observational record, CPOL is a unique tool for research.

Internal calibration of CPOL is performed at the beginning of each wet season. Therefore, any change in radar calibration that could happen during a season cannot be tracked using internal calibration. It was a major motivation of this present work to monitor the CPOL calibration using external sources. The first step is to calibrate the receiver gain by injecting a known noise source and to adjust the noise level of CPOL. A single-point calibration procedure (injecting a known signal at a known injection point) is used to calibrate the receiver chain. In short, a known signal power is injected into the receiver via the forward port of the system's bidirectional waveguide coupler. The system is made to record the response of the analog-to-digital converter, the receiver being linear means only a pair of points is needed to establish the transfer curve. Likewise, the transmitted power is checked from the same forward port of the bidirectional coupler. The unknowns between the transmitter and the receiver then reduce to the waveguide loss, antenna gain, and radome loss. A solar calibration procedure using the sun as a known backscattered-power target is then used to calculate the antenna gain and the waveguide losses. More details about these internal calibration procedures are available in Chandrasekar et al. (2015).

The calibration of CPOL, using our integrated approach, is evaluated for all available wet seasons between 1998 and 2017. During that period three seasons are missing: 2000/01, 2007/08, and 2008/09. The first season is missing because the radar was moved to Sydney, Australia, to support the 2000 Sydney Olympic Games (Keenan et al. 2003). The two latter seasons are missing because the radar antenna and receiver needed replacement. There are thus 17 wet seasons available out of this 20 -yr period. Outside of the wet season, CPOL is shut down for maintenance because there is very limited precipitation.

The cross-correlation coefficient is corrected for low signal-to-noise ratio using an algorithm adapted from Bringi et al. (1983). The differential phase $\phi_{\mathrm{dp}}$ is evaluated using the linear programming algorithm described in Giangrande et al. (2013). The attenuation on the horizontal reflectivity is corrected using the algorithm by $\mathrm{Gu}$ et al. (2011). The two latter techniques and algorithms are part of the Python ARM Radar Toolkit (Py-ART) (Helmus and Collis 2016). The specific differential attenuation $A_{\mathrm{dp}}$ on $Z_{\mathrm{dr}}$ is estimated using a linear $A_{\mathrm{dp}}-K_{\mathrm{dp}}$ relationship (Bringi et al. 1990).

\section{b. Spaceborne precipitation radars}

The Precipitation Radar (PR) on board TRMM operated almost continuously from December 1997 to April 2015, with reliable measurements up to September 2014 (Kummerow et al. 1998). Its minimal detectable reflectivity is around $18 \mathrm{dBZ}$. A scan is composed of 49 sample beams within the cross-track swath of $215 \mathrm{~km}$ prior to an orbit boost in August 2001 and $247 \mathrm{~km}$ 
afterward. The horizontal resolution was $4.3 \mathrm{~km}$ before the boost and $5 \mathrm{~km}$ after $\left( \pm 17^{\circ}\right.$ from the path center), and the vertical resolution is $250 \mathrm{~m}$. Version 7 of the 2A23 (precipitation type and brightband characteristics) and the 2A25 (corrected reflectivity) products are used for our comparisons. Precipitation type is determined using the horizontal and vertical echo structures (Awaka et al. 2009). To correct for attenuation, which is substantial in convective cores at Ku band, a hybrid method (Meneghini et al. 2004) combining the approach of Hitschfeld and Bordan (1954) and Meneghini et al. (2000) is used.

The GPM satellite carries the Dual-Frequency Precipitation Radar (DPR) working at $\mathrm{Ka}$ and $\mathrm{Ku}$ bands. The Ku-band radar is similar to the PR on TRMM, with a cross-track swath of $245 \mathrm{~km}$. The nominal sensitivity of the KuPR is $18 \mathrm{dBZ}$, the same as TRMM (Hou et al. 2014); however, prelaunch tests showed that it could detect as low as $14.5 \mathrm{dBZ}$ (Toyoshima et al. 2015). Version 5 of the $2 \mathrm{AKu}$ product has been used for this study. It is available from March 2014 onward, and it contains the same information as the $2 \mathrm{~A} 23$ and $2 \mathrm{~A} 25$ TRMM products.

\section{c. Disdrometer}

Observations of the drop size distribution from an impact disdrometer are used for the self-consistency technique. The disdrometer is located at the U.S. Department of Energy Atmospheric Radiation Measurement (ARM) central facility, near Darwin airport $\left(-12.425^{\circ} \mathrm{N}, 130.892^{\circ} \mathrm{E}\right)$, about $25 \mathrm{~km}$ southwest of CPOL. A Python implementation of the T-matrix algorithm has been used to compute $Z_{h}, Z_{\mathrm{dr}}$, and $K_{\mathrm{dp}}$ from disdrometer measurements (Leinonen 2014). These results are then used to derive a self-consistent relationship for this tropical area.

\section{The RCA technique: Using ground clutter to monitor reflectivity calibration}

\section{a. Introduction}

Persistent echoes close to the radar are generally caused by buildings, roads, topographic structures, or biological markers like trees. For stationary clutter echoes $(r=$ constant) with constant scattering properties $\left(P_{r}=\right.$ constant $)$, it can be seen from Eq. (2) that any change in reflectivity over time must be due to a change in the radar constant:

$$
\Delta Z_{c}=\Delta(10 \log C),
$$

where $Z_{c}$ is the ground clutter reflectivity. The main assumption of the RCA technique is that any variation in ground clutter reflectivity is caused by a change in radar calibration. A statistical analysis of the reflectivity of these fixed echoes can be used to monitor the radar calibration.

To use the RCA technique, a map of close-range clutter is first generated by looking at the position of high-reflectivity nonmeteorological echoes. We look only at the nonmeteorological echoes from the first elevation. Nonmeteorological echoes are defined by $\rho_{\mathrm{hv}}<0.5$ and $v=0 \mathrm{~m} \mathrm{~s}^{-1}$. The frequency of occurrence of ground clutter is then computed for the closest $10-\mathrm{km}$ range around the radar for a set of clear-sky data to derive a "clutter map." Wolff et al. (2015) proposed retaining only those pixels with a frequency of occurrence above $50 \%$. Because there are numerous clutter points around CPOL, we applied a higher threshold of $95 \%$ so that only the most robust echoes are retained.

Once we have the position of permanent clutter echoes, we then parse the entire dataset and extract the reflectivity of the clutter echoes.

Silberstein et al. (2008) proposed using the 95th percentile of the ground clutter reflectivity distribution to monitor the radar calibration. By determining a baseline for the clutter reflectivity distribution $Z_{c, \text { ref }}$, we can determine the relative calibration offset (Silberstein et al. 2008; Wolff et al. 2015):

$$
\mathrm{RCA}_{\text {offset }}(\mathrm{dB})=Z_{c, \text { ref }}-\operatorname{CDF}\left[Z_{c}, 95 \%\right] \text {, }
$$

where $\operatorname{CDF}\left[Z_{c}, 95 \%\right]$ is the 95th percentile of the ground clutter reflectivity, called the RCA value. The RCA value is the offset that has to be applied to the reflectivity in order to obtain agreement with the established baseline.

Figure 1 shows the clutter selection procedure for three different seasons: 1998 (Figs. 1a-c), 2006 (Figs. 1d-f), and 2013 (Figs. 1g-i). The left column is the mean reflectivity of all nonmeteorological echoes for 1 week of data, the center column is the frequency of occurrence (\%) of each echo, and the right column is the derived clutter map (i.e., $\overline{Z_{h}}>40 \mathrm{dBZ}$ and $f>95 \%$ ). The clutter mask of 2006 retains 3034 points (Fig. 1f), while the clutter masks of 1998 and 2013 retain around 1000 points (Figs. 1c,i). This is caused by a problem with the CPOL elevation angle drive. Both Silberstein et al. (2008) and Wolff et al. (2015) denoted that the RCA could also be used to monitor change in the elevation angle, as the RCA is very sensitive to it. By varying the elevation angle from $0.9^{\circ}$ to $0.8^{\circ}$, they found a $1-\mathrm{dB}$ increase in the RCA value. The RCA value for CPOL increases more during that period, by almost $5 \mathrm{~dB}$, but we are looking at clutter with a much lower elevation angle; therefore, we probably have a more direct, and thus higher, clutter reflectivity. 

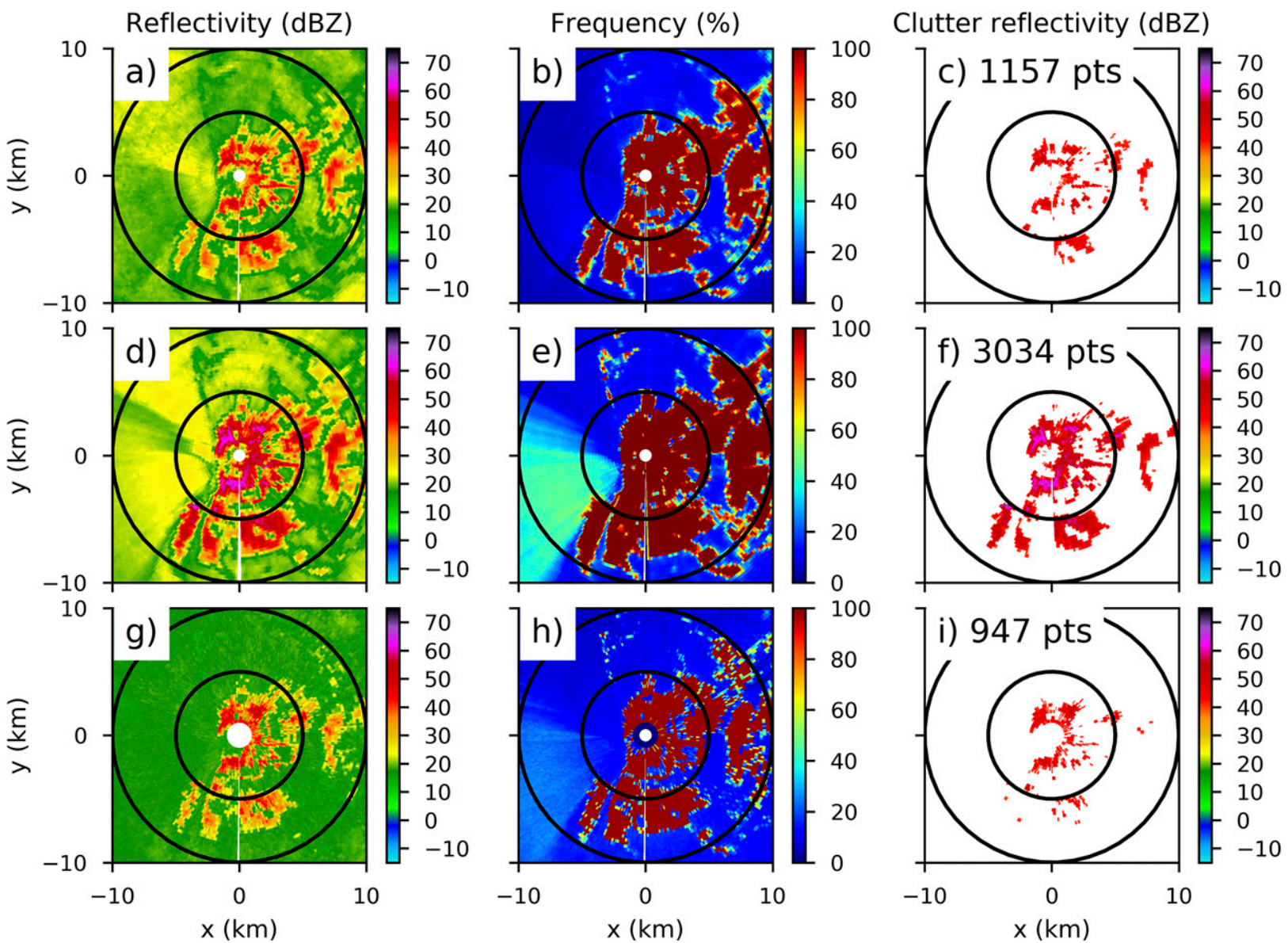

FIG. 1. (a),(d),(g) Mean reflectivity, (b),(e),(h) frequency, and (c),(f),(i) clutter mask for 1 week of data in (a)-(c) 1998, (d)-(f) 2006, and (g)-(i) 2013. Isoradials are shown every $5 \mathrm{~km}$.

These different masks, shown in Figs. 1c, 1f, and 1i, impact the RCA value, because the clutter reflectivity distributions are different. In fact, if the mask of 1998 is used on data from 2013 while being similar at face value, it causes the RCA values to change by $4 \mathrm{~dB}$. The RCA baseline of one season should not be compared to another if the clutter maps are different. In the following work, we always treated each season independent of one another and made a new clutter mask at the beginning of each season.

\section{b. Impact of rain on ground clutter reflectivity}

\section{1) DAILY VARIATIONS}

Wolff et al. (2015) suggested that precipitation had little to no effect on the RCA technique, as the associated reflectivities are usually considerably lower than the 95th percentile of the ground echo reflectivity. However, no quantitative study was conducted to quantify this effect. So, to study the impact of precipitation on our RCA value, we have estimated the average rainfall rate within a $5-\mathrm{km}$ range from the radar. Because we are working with the raw, uncorrected, and uncalibrated data (i.e., the calibration has not been adjusted with an external source, and noise and anomalous propagation have not been removed), only a rough estimation of rainfall rate is achievable, sufficient for the purpose of this sensitivity analysis. A general $Z-R$ relationship, $Z=300 R^{1.35}$ (Jorgensen and Willis 1982) is used to estimate the rainfall rate.

Figure 2a shows the maximum, mean, median, and 95th and 99th percentiles of the ground clutter reflectivity distribution. Figure $2 b$ shows the average rainfall rate for the first 5-km range around the radar, for CPOL, for all scans from 1 January 2017. Figure 2b indicates that there is no precipitation above the radar site before noon. Of all the different statistics for the ground clutter reflectivity distribution (Fig. 2a), the 95th percentile and the 99th percentile, as well as the maximum, stay stable when there is precipitation. In Fig. 2a, during the dry period, the 95th and 99th percentiles, and the maximum have values of $44.0 \pm 0.1,47.1 \pm 0.4$, and 

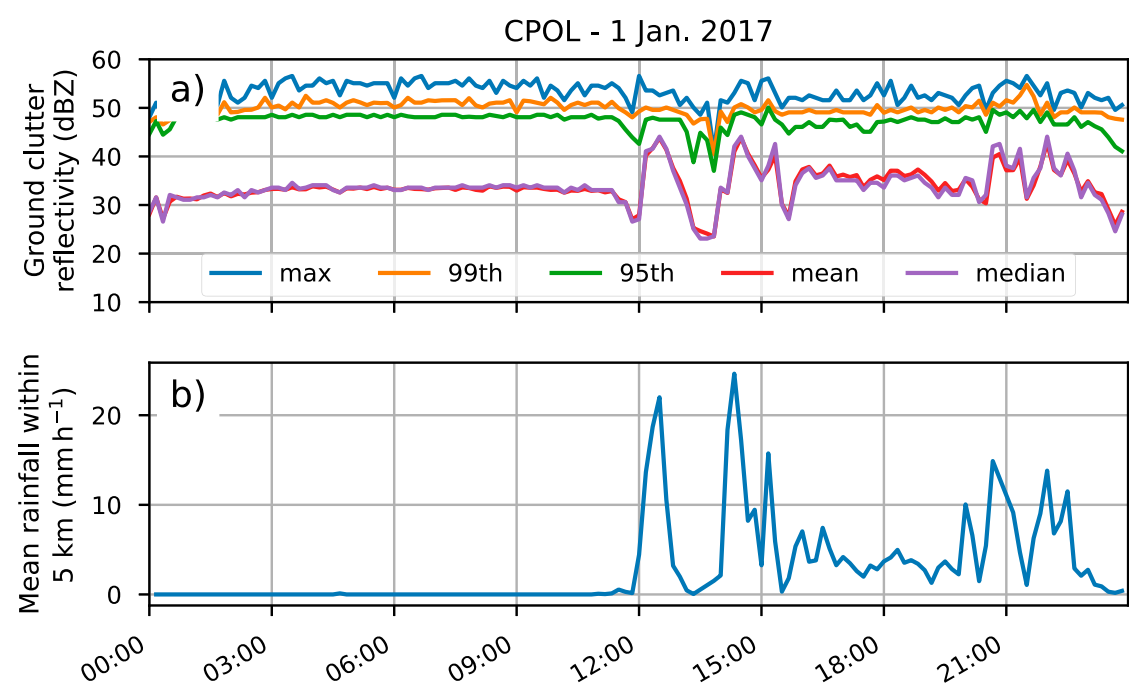

FIG. 2. (a) Maximum, mean, median, and 99th and 95th percentiles of the ground clutter reflectivity distribution for CPOL on 1 Jan 2017. (b) Average rainfall-rate estimate within the first $5-\mathrm{km}$ range from the radar.

$50.8 \pm 0.6 \mathrm{dBZ}$, respectively. During the wet period, the 95th and 99th percentiles, and the maximum have values of $43.7 \pm 0.4,46.3 \pm 0.9$, and $50.4 \pm 1.2 \mathrm{dBZ}$, respectively. Clearly, the 99th and 95th percentiles are the least impacted by precipitation. During the dry period, the rate of precipitation shows almost no variability. The variability during rain period is more important; we can see a drop at the 95th percentile of about $2.5 \mathrm{~dB}$ at 1200 UTC (the beginning of rain) and drops of 3-4 dB at about 1300-1400 UTC. It returns to its baseline value afterward. Even if these drops in 95th percentiles are relatively important, because they are localized, the daily statistics are only slightly affected. The variations caused by rain on the whole day are of about $0.4 \mathrm{~dB}$. Yet, it is easy to remove scans contaminated with rain close to the radar and the user of the RCA technique should do so. Moreover, it validates the idea, proposed by Silberstein et al. (2008), to use the 95th percentile of ground clutter reflectivity for monitoring the radar calibration.

\section{2) SEAsonal VARiations}

Figure 3 shows the RCA value for all radar scans for season 2002/03, when there is no rain at the radar site (Fig. 3a) and in presence of rain (Fig. 3b). The standard deviation of the seasonal-mean RCA value is only slightly $(0.1 \mathrm{~dB})$ higher in the presence of rain, although there are notably more outliers. The mean itself is also lower when rain is present. This is true across all seasons (not shown) and it may be the result of wet radome attenuation. However, the difference is small and, critically, within the calibration accuracy target of $0.5 \mathrm{~dB}$. Also, Fig. 3 clearly shows two drops in radar calibration, relative to the season mean RCA baseline of $64.3 \mathrm{dBZ}$. The first drop of $4.6 \mathrm{~dB}$ appears on 5 November 2002, before going back to the reference value on 7 November 2002. A second drop of $4.9 \mathrm{~dB}$ appears between 18 and 30 March 2003. These drops correspond to changes in radar calibration, and the first step in correcting them is to offset the reflectivity of these periods toward the baseline.

\section{c. Seasonal monitoring of the radar calibration}

The RCA technique can be used to monitor radar calibration and pinpoint times when it changes. Because of the sheer number of scans performed every day, estimating the daily mean of the RCA value is a more sensible approach to reduce radar noise and fluctuations in the nature of clutter (moving trees for instance). This daily averaging acts to smooth RCA values and makes the impact of rain even more negligible (not shown). Thus, discrimination between wet and dry scans is not shown anymore, and the RCA is computed for all scans.

The 17 seasons of CPOL data are processed using the RCA technique. Most seasons show a similar pattern: long periods of time when the RCA is stable around a value, which becomes the de facto seasonal baseline, with interleaving shorter-duration periods when the RCA value is higher or lower (e.g., Fig. 4 for season 2013/14). Figures 4 and 5 show the RCA value for all radar scans, the daily average, and the daily variations of the RCA value relative to a baseline, for seasons 2013/14 (Fig. 4), and 2015/16 (Fig. 5). These figures show how stable the RCA value is, even if episodes of rain are not excluded. The standard deviation of the daily RCA values, for the baseline period, in $2013 / 14$ is $0.03 \mathrm{~dB}$ 

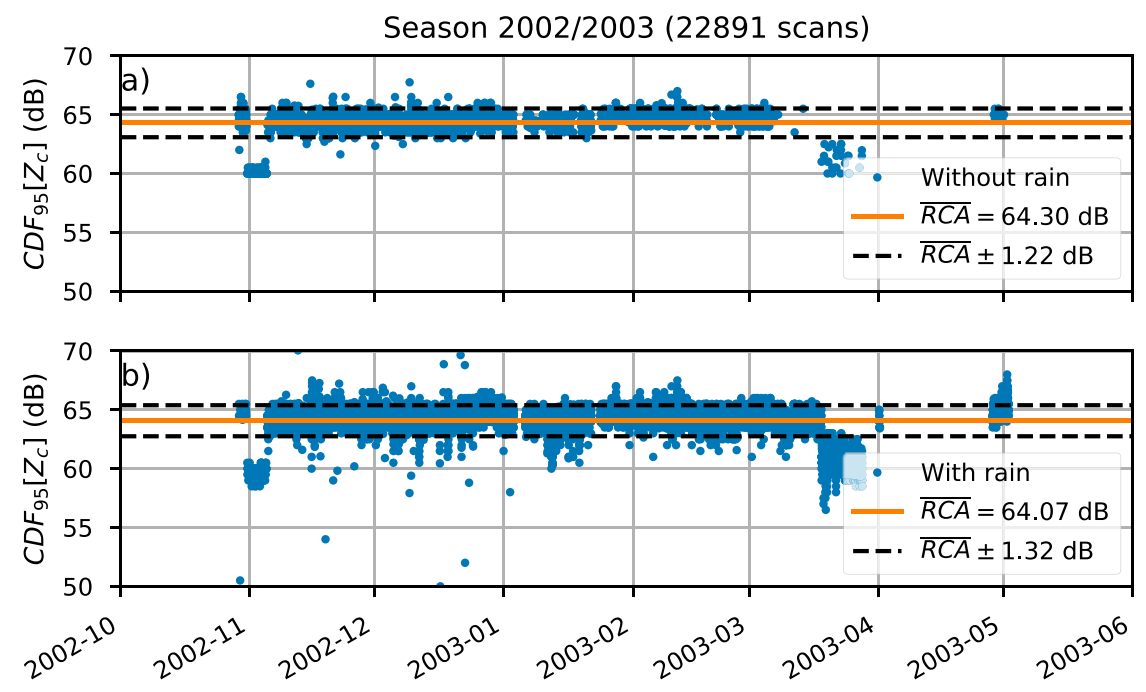

FIG. 3. The 95th percentile of the clutter reflectivity for all CPOL scans for season 2002/03 (a) without and (b) with rain in the 5-km range around the radar site. There are 7103 scans without rain and 15788 scans with rain at the radar site. The solid line represents the seasonal mean of the RCA. The dashed lines represent plus and minus one standard deviation around the seasonal mean of the RCA distribution.

(Fig. 4b) and $0.04 \mathrm{~dB}$ for 2015/16 (Fig. 5b). The date and the value of changes in calibration, compared to the RCA baseline value, are represented by red dots in Figs. $4 \mathrm{c}$ and $5 \mathrm{c}$.

For season 2013/14, the first day of measurement is 16 October 2013, and for the first 2 days, CPOL's RCA value is around $47.8 \mathrm{~dB}$. Then, from 18 October to 5 November 2013, the RCA value increases to $49.2 \mathrm{~dB}$. After 5 November, the RCA shows an unique stable value of $47.7 \mathrm{~dB}$. This last value is the baseline for season 2013/14. The data are corrected for seasonal variations of the calibration by offsetting the reflectivity toward the
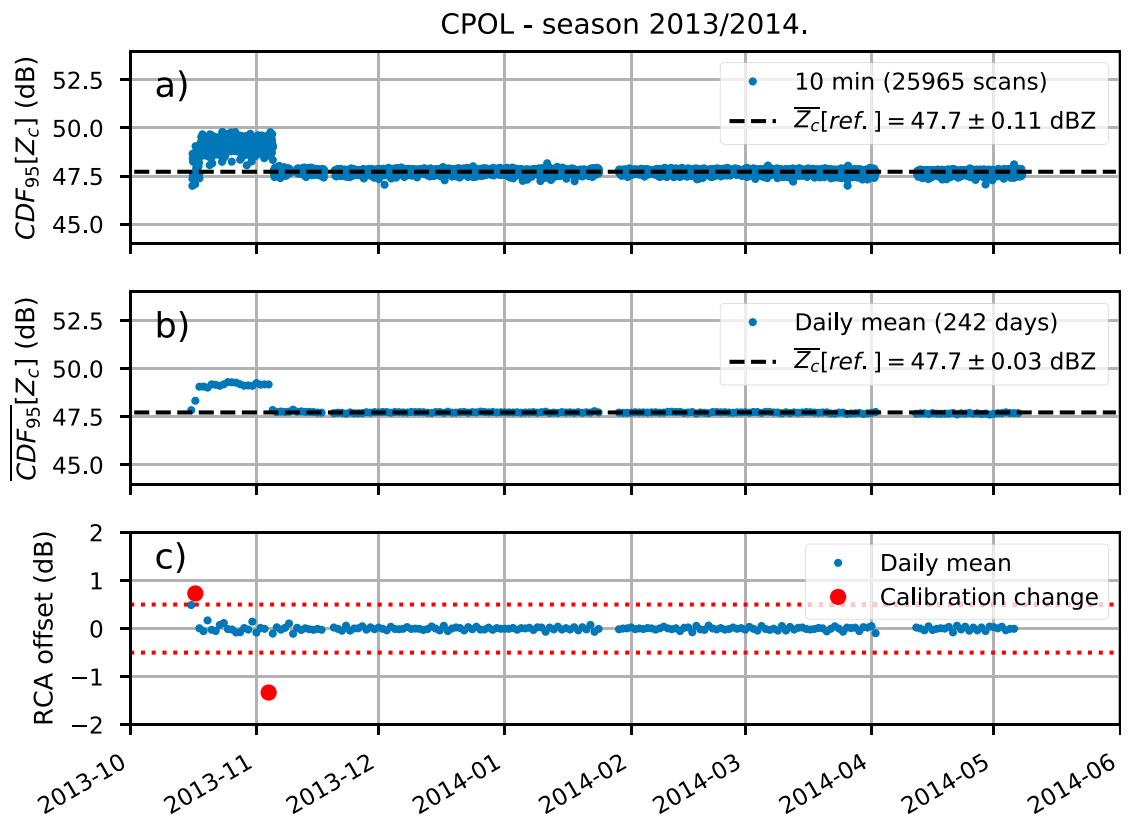

FIG. 4. Results of the ground echo monitoring technique for season 2013/14 of CPOL. The 95th percentiles of clutter reflectivity (a) for each PPI and (b) daily average. (c) The daily variation of the relative calibration value. Red dots represent the day when a calibration change occurs. Red dashed lines represent the $\pm 0.5-\mathrm{dB}$ threshold used to define a change in calibration. 

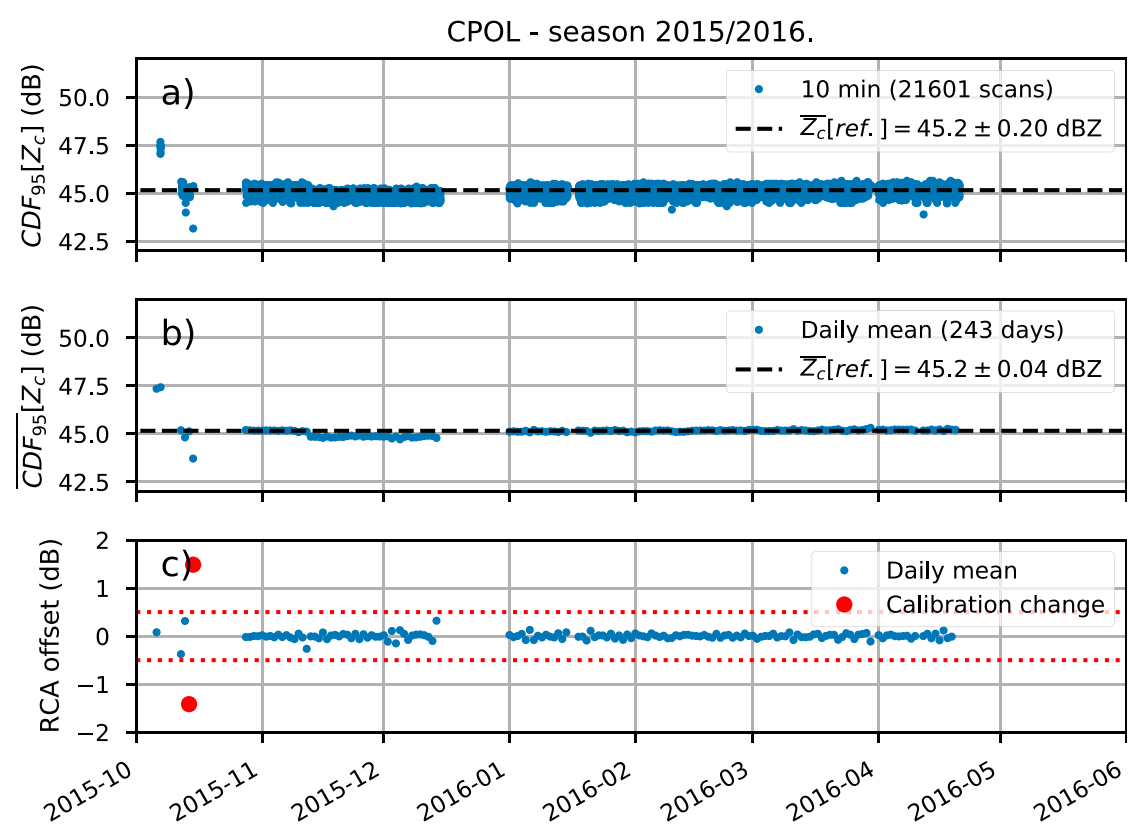

FIG. 5. As in Fig. 4, but for season 2015/16.

baseline every time the reflectivity distribution differs from the baseline. For Fig. 4, it concerns the period from 18 October to 5 November 2013. These two days correspond to modifications to the CPOL calibration by the radar engineer on site.

In 2015/16, after the first day of data, the RCA value remains stable for the rest of the season (Fig. 5). Between 12 November and 15 December 2015, one can notice a drop in the RCA value, and this is particularly visible in Fig. 5b. This change has not been corrected, as it is below our somewhat conservative threshold value of $0.5 \mathrm{~dB}$. Yet, it clearly demonstrates the sort of accuracy that can be achieved with the RCA technique. We should note that even though the statistics behind the RCA give results with low variability, the radar quantization of the reflectivity is $0.5 \mathrm{~dB}$. Even though the RCA can monitor change below $0.5 \mathrm{~dB}$, it still means that the accuracy of the RCA technique is bound by the quantization of radar data, thus $0.5 \mathrm{~dB}$.

Although the RCA technique allows for accurate monitoring and adjustment of reflectivity offset changes, it provides only a relative calibration, as the baseline is not compared to an external reference of reflectivity. To estimate a reference value of calibration offset for that baseline, we use comparisons with spaceborne radars.

\section{Calibrating CPOL reflectivities with spaceborne radars}

The ground radar (GR) calibration technique using TRMM and GPM PR reflectivity measurements as the external reference is described in detail in Warren et al.
(2018). TRMM and GPM reflectivity is corrected from the attenuation. In short, it is a volume-matching method that allows quantitative comparison of the reflectivity of spaceborne radars (SR) and ground radars, with minimal spatial processing of the two datasets. Intersections between the radar beams are identified and the reflectivities from both instruments are spatially averaged to an approximately common sample volume.

We use the same set of requirements as in Warren et al. (2018). The maximum delay between spaceborne and ground radar measurements is $300 \mathrm{~s}$. A minimum of 10 satellite profiles inside the ground radar area is required for comparison. This corresponds to a surface area of about $\sim 250 \mathrm{~km}^{2}$. The only notable differences with Warren et al. (2018) are that we compare only the liquid phase. Warren et al. (2018) suggested that there may be overcorrection of attenuation in heavy stratiform rain (reflectivities above $\sim 36 \mathrm{dBZ}$ ); however, for most stratiform samples (which have lower reflectivities), the agreement was good and attenuation (and thus the correction) is minimal. We found good agreement between GR and SR reflectivity above and below the bright band in stratiform precipitation and so used both in our previous study. However, because these frequency conversions of the reflectivity tend to be less accurate for the ice phase than for the liquid phase, we decided in the present paper to exclude the ice phase as well (CPOL being located in the tropics, we have enough values in the liquid phase). In convective precipitation, Warren et al. (2018) found a systematic decrease in GR-SR reflectivity with height, suggesting a systematic undercorrection of 
attenuation at low levels. Therefore, convective samples were excluded from the analysis.

The reflectivity of spaceborne radars is converted to $\mathrm{C}$ band by using results from the T-matrix calculation (more details on the T-matrix parameterization in section 5). The $\mathrm{T}$ matrix allows us to compute the reflectivity from the disdrometer measurements at $\mathrm{C}$ and $\mathrm{Ku}$ bands. As shown in Fig. 6, using a similar method as $\mathrm{Cao}$ et al. (2013) for converting reflectivity from $\mathrm{Ku}$ to $\mathrm{S}$ band, we found that the dual-frequency ratio (DFR) between the $\mathrm{C}$ and $\mathrm{Ku}$ bands can be approximated by a fourth-order polynomial:

$$
\begin{aligned}
\operatorname{DFR}(x)= & 1.21 \times 10^{-6} x^{4}-1.23 \times 10^{-4} x^{3} \\
& +6.38 \times 10^{-3} x^{2}-0.15 x+0.53,
\end{aligned}
$$

where $x$ is the Ku-band reflectivity. Therefore, the C-band reflectivity is $Z_{C}=Z_{\mathrm{Ku}}+\operatorname{DFR}\left(Z_{\mathrm{Ku}}\right)$. The accuracy of this conversion is about $\pm 0.5 \mathrm{~dB}$ for $10 \leq Z<30 \mathrm{~dB} Z$ and about $\pm 1 \mathrm{~dB}$ for $Z>30 \mathrm{~dB} Z$ (Fig. 6). Note that this relation is valid for $Z \in[10 ; 60] \mathrm{dB} Z$, for the liquid phase only, and in the tropics.

TRMM PR data have been used for seasons between 1998 and 2014, while GPM PR data have been used for seasons after 2014. Because of our stringent requirements, between 15 and 30 cases match for comparison each season.

\section{a. GR-PR comparison for one match}

Figures $7 \mathrm{a}$ and $7 \mathrm{~b}$ show the probability density functions (PDFs) of CPOL and TRMM reflectivities for 19 January 2014 before (Fig. 7a) and after (Fig. 7b) calibrating CPOL. Figures $7 \mathrm{c}$ and $7 \mathrm{~d}$ show the PDF of reflectivity difference between CPOL and TRMM $\left(\Delta Z_{h}=Z_{h}[\mathrm{GPM}]-Z_{h}[\mathrm{CPOL}]\right)$, before (Fig. 7c) and after (Fig. 7d) CPOL calibration. Before calibration, Figs. $7 \mathrm{a}$ and $7 \mathrm{c}$ clearly show that CPOL is running $\sim 2.1 \mathrm{dBZ}$ hot relative to GPM. By applying this $-2.1-\mathrm{dB}$ offset on CPOL, reflectivity distributions are then in much better agreement with similar PDF shapes (Figs. 7c) and by construction result in a much lower reflectivity difference $\overline{\Delta Z_{h}}=0.1 \mathrm{~dB}$ (Fig. 7d).

The TRMM PR has a minimum sensitivity level of about $18 \mathrm{dBZ}$, while it is $14 \mathrm{dBZ}$ for GPM. For the volume-matching technique, only space radar reflectivities above this level are included in the calculation. A threshold of $10 \mathrm{~dB} Z$ is taken for the GR reflectivity. Warren et al. (2018) showed that the reflectivity differences derived using the volume-matching method can vary substantially (by more than $1 \mathrm{~dB}$ ) depending on the value of the GR reflectivity threshold. If $\Delta Z_{h}>0$, then some points that were ignored because of the reflectivity threshold may now be part of the $Z_{h}$ distribution. Conversely, if $\Delta Z_{h}<0$, then some points of the CPOL $Z_{h}$ distribution

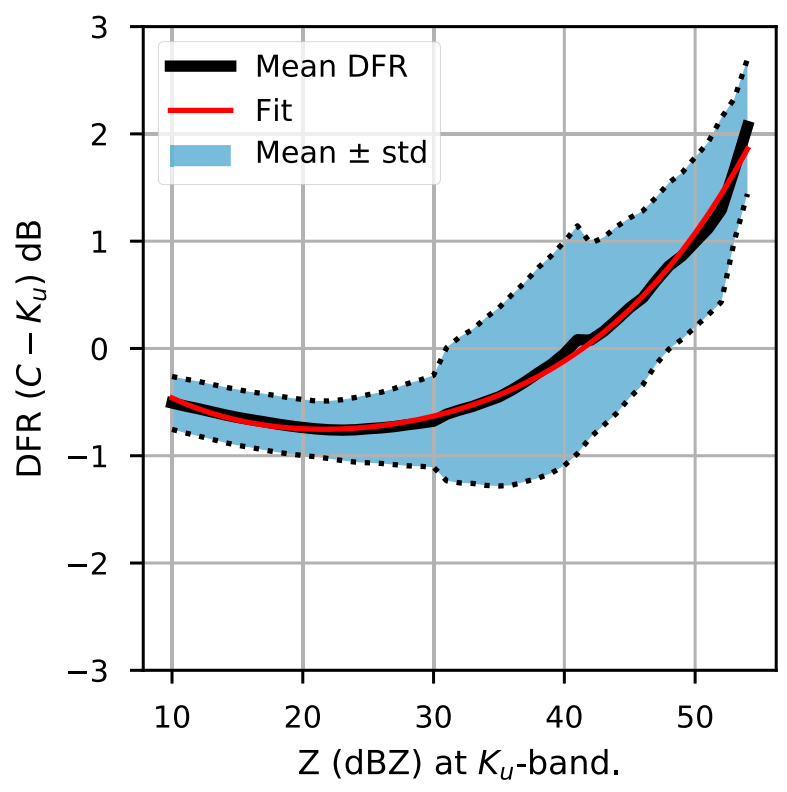

FIG. 6. The characteristics of $\mathrm{C}$ and $\mathrm{Ku}$ bands for rain. Dependence on the dual-frequency ratio in the function of the Ku-band reflectivity. The black solid line represents the mean relation, whereas the black dotted lines denote plus and minus one standard deviation. The red line is the mean relation fitted to the data point [Eq. (5)].

that were included may be now dismissed. To mitigate this effect, we use a similar iterative procedure as the one present in Warren et al. (2018), based on Protat et al. (2011), which largely reduced the variation between the GR and PR reflectivity distributions (Fig. 8).

The correction procedure shown in Fig. 8 (the SCARintegrated approach) works this way: 1) we use the RCA technique to correct toward one baseline all the variability in the radar calibration for one season (section 3). 2) We use the volume matching presented herein and determine the $\Delta Z_{h}$ offset needed to obtain agreement with TRMM or GPM. 3) If $\left|\overline{\Delta Z_{h}}\right| \leq 0.5 \mathrm{~dB}$, then the procedure stops and CPOL is considered calibrated. If not, then an offset equal to $\overline{\Delta Z_{h}}$ is applied on CPOL reflectivity and the whole comparison is started again until $\left|\overline{\Delta Z_{h}}\right| \leq 0.5 \mathrm{~dB}$. A maximum of three iterations was required to achieve convergence for all seasons in the CPOL dataset. This iterative procedure was found to reduce the standard deviation of the $\Delta Z_{h}$ distribution and thus to achieve a better statistical agreement between CPOL and TRMM-GPM (Figs. 7c,d).

\section{b. GR-PR comparison for one season}

The SCAR-integrated method allows us to automatically adjust the calibration of ground radars. Here we detail how we use it on one season (2013/14) of data. PDFs of $Z_{h}$ and $\Delta Z_{h}$ are evaluated every time there is a match between CPOL and TRMM-GPM. Figure 9a 

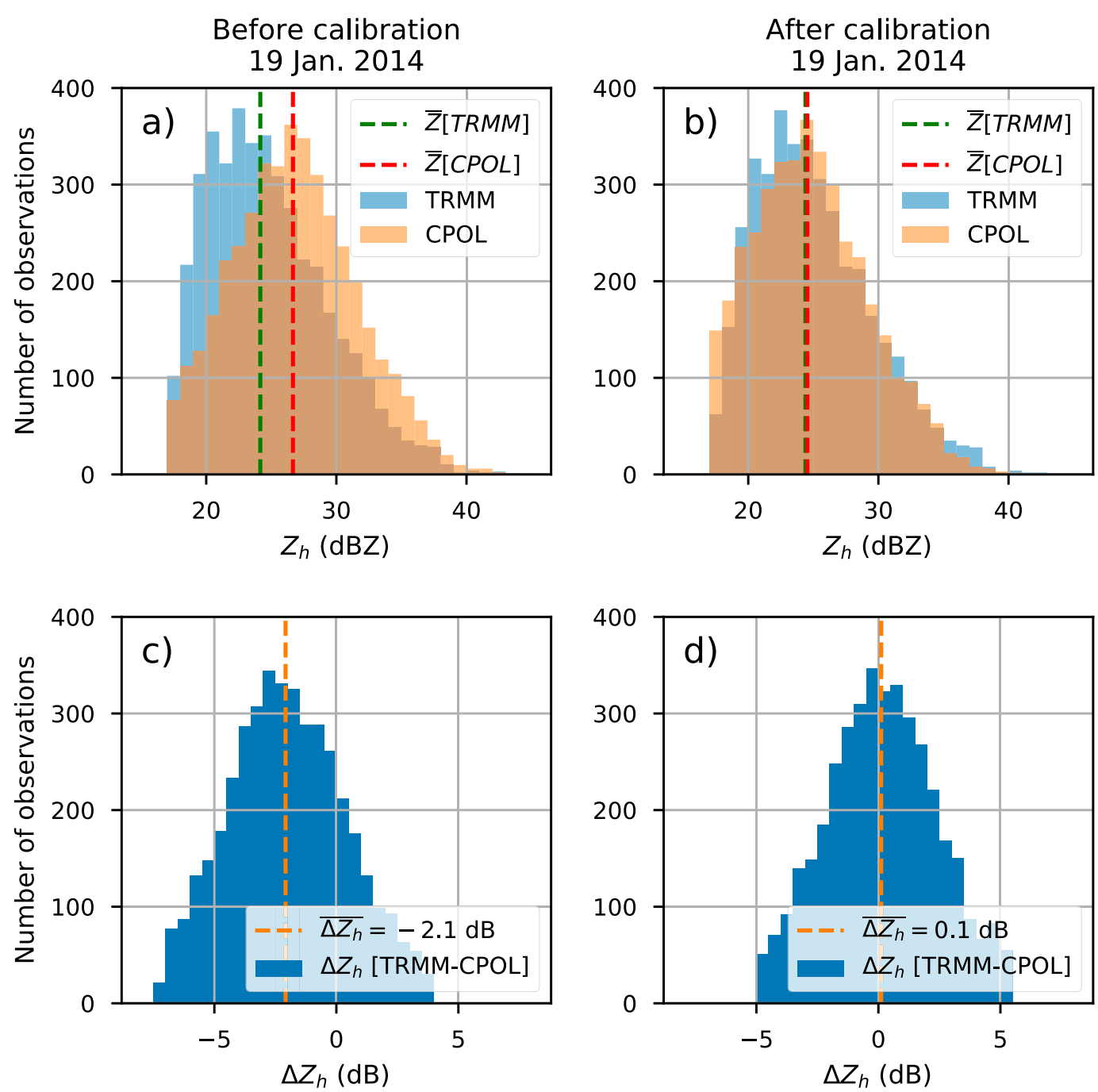

FIG. 7. (a),(b) Histograms showing TRMM (blue) and CPOL (orange) reflectivity distributions for 19 Jan 2014, and (c),(d) the reflectivity difference $\left[\Delta Z_{h}=Z_{h}(\mathrm{TRMM})-Z_{h}(\mathrm{CPOL})\right]$ between TRMM and CPOL. (a),(c) Before and (b),(d) after calibrating CPOL. (a),(b) The green dashed line is the reflectivity distribution average for GPM and the red dashed line is for CPOL. (c),(d) The orange dashed line is the $\Delta Z_{h}$ distribution average.

shows the time series of $\Delta Z_{h}$ for the uncalibrated CPOL data over season 2013/14. The seasonal average is computed for the whole period. Because the sample size can be very different for each match, we also calculated the weighted average. The sample size on 20 and 23 November, 30 December, and 12 March is $3868,728,1234$, and 2931 volumes, respectively, while it is below 150 for the other dates. By weighting the seasonal $\Delta Z_{h}$ average with the sample size, $\overline{\Delta Z_{h}}=0.6 \mathrm{~dB}$, while the nonweighted average is $\overline{\Delta Z_{h}}=0.7 \mathrm{~dB}$, with all matches included $\overline{\Delta Z_{h}}=1.3 \mathrm{~dB}$, with the first match (5 November 2013) excluded.

To obtain the results displayed in Fig. 9b, we correct $Z_{h}$ from the variations found by the RCA. Because the RCA technique shows a stable value of $47.5 \mathrm{~dB}$ after 7 November 2013 (cf. Fig. 4), this value is used as a baseline to correct CPOL reflectivity for season 2013/14. It means that CPOL reflectivity between 18 October and 6 November 2013 is adjusted by the value of the RCA offset [cf. Eq. (4)]. Figure 9b clearly shows that the first match (5 November 2013) has been shifted to similar values as those afterward. The other matches are not affected by the RCA correction, as their RCA value is already the RCA baseline.

We then use the value of $0.9 \mathrm{~dB}$ found for the weighted average in Fig. 9b as an offset to GR reflectivity. Finally, we run the volume-matching technique once again to get Fig. 9c. Because the new season average is below $\overline{\left|\Delta Z_{h}\right|} \leq 0.5 \mathrm{~dB}$, the procedure stops and the reflectivity is considered calibrated after the second iterative pass. The weighted seasonal $\Delta Z_{h}$ average is actually the offset 


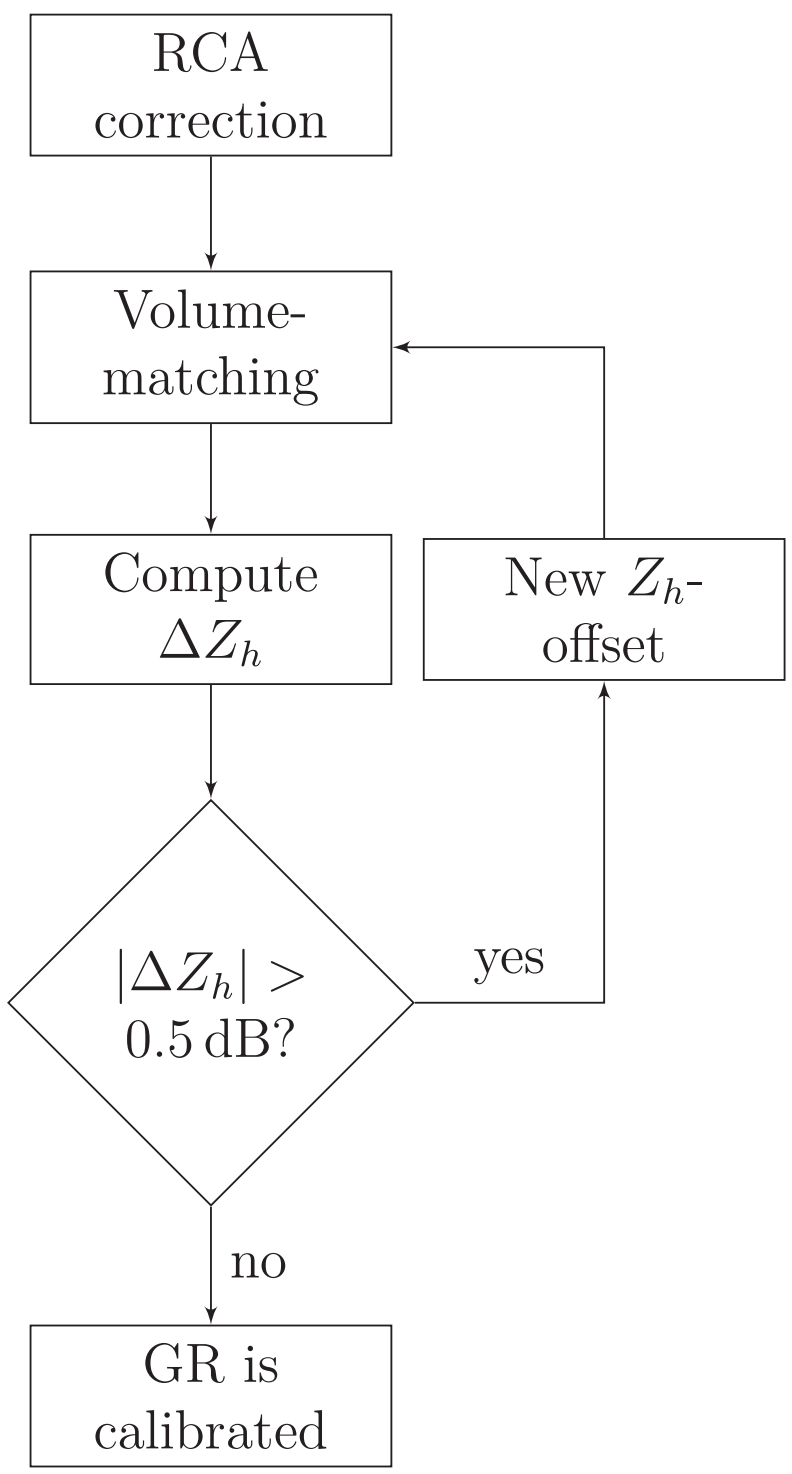

FIG. 8. Flowchart of the iterative procedure for using the volumematching technique.

that is needed to transform the RCA baseline into the reference value of calibration, for that season. Note that if we had used a baseline of about $46.5 \mathrm{dBZ}$ for the RCA, then we would have immediately reached an agreement between GR and TRMM PR reflectivities. This is consistent all along the period between 2009 and 2014 (period for which TRMM is used for comparison). However, this is an a posteriori result and we would not have been able to find this baseline value with the RCA technique alone.

\section{c. Comparison of TRMM-GPM and CPOL between 1998 and 2017}

The SCAR-integrated method has been applied to the entire CPOL dataset, between 1998 and 2014. Figure 10 shows the comparison of the reflectivity distribution of CPOL against TRMM from 1998 to 2014 (Figs. 10a,c) and GPM from 2014 to 2017 (Figs. 10b,d) before (Figs. 10a,b) and after (Figs. 10c,d) CPOL calibration. The comparison with TRMM corresponds to 301 matches (34 for GPM) for a total of more than 255000 individual volume-matched samples (20000 for GPM). For TRMM, the Pearson correlation coefficient $r$ before calibration is 0.78 ( 0.89 for GPM); data are scattered and several peaks in the density distribution can be observed. After calibration, Fig. 10c shows that CPOL and TRMM are in much better agreement (Fig. 10d for GPM), with $r=$ 0.90 ( 0.91 for GPM) and less scatter around the 1:1 line.

In conclusion, the use of the RCA technique, for correcting precisely all the daily variations to a unique baseline, coupled with the satellite volume-matching method, to find the reference calibration value of that baseline, has been shown to be a robust approach to calibrate ground radars.

\section{Disdrometer-based approaches}

Gorgucci et al. (1992) first noted a very robust relationship between $K_{\mathrm{dp}} / Z_{h}$ and $Z_{\mathrm{dr}}$ in rain, which was referred to as the "self-consistency" relationship, later generalized by Scarchilli et al. (1996) and Gorgucci et al. (2006). Various studies then used the self-consistency approach for calibrating radars (Goddard et al. 1994; Vivekanandan et al. 2003; Gourley et al. 2009; Marks et al. 2011, among others). To develop a relationship for our geographical location, we first compute a selfconsistency relationship using our calibrated CPOL dataset, where $Z_{h}$ is calibrated using the method presented previously, and $Z_{\mathrm{dr}}$ is calibrated using the birdbath technique. Next, we use data from an impact disdrometer present in 2006 at the Darwin ARM site (about $25 \mathrm{~km}$ southwest of CPOL) to derive a set of self-consistent relationships using T-matrix calculations and different values of the standard deviation of the canting angle and different drop-shape models available in the literature. We then assess which set of assumptions best approximates the reference CPOL self-consistent relationship. Third, we assess the suitability of the self-consistency technique for calibrating $Z_{h}$. Finally, we use the CPOL dataset and the self-consistency to assess the potential of this self-consistency technique for $Z_{\mathrm{dr}}$ calibration.

\section{a. The self-consistency technique}

The polarimetric variable $\phi_{\mathrm{dp}}$ is processed using the algorithm of Giangrande et al. (2013). This method applies a Sobel filter to compute $K_{\mathrm{dp}}$, to smooth the data, and to mitigate the impact of the noise on the retrieval. The same smoothing filter has been applied 
Comparison CPOL/TRMM - season 2013/2014
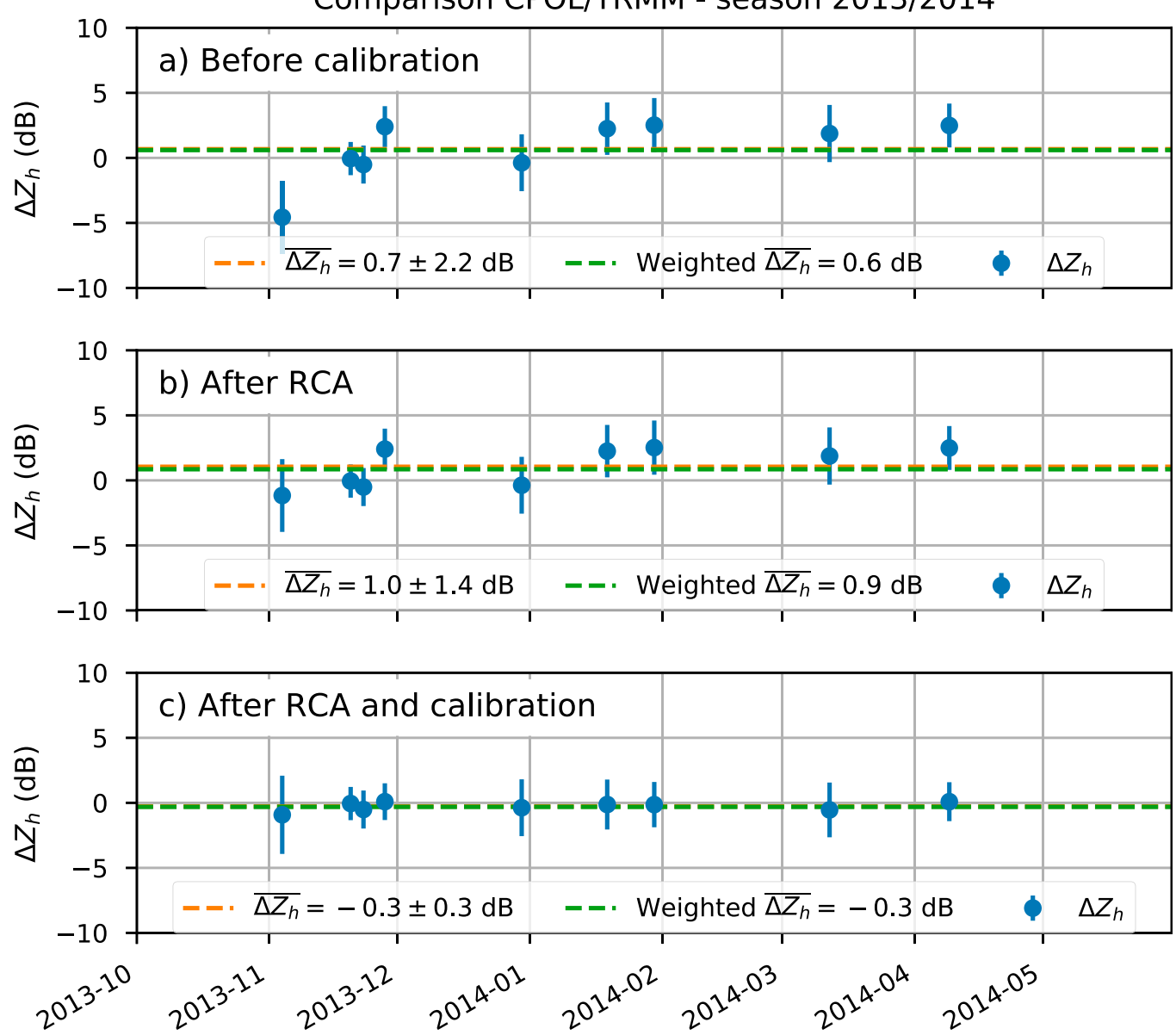

FIG. 9. Time series of the CPOL-TRMM reflectivity difference $\Delta Z$ with their error bars for season 2013/14. The error bars represent plus and minus one standard deviation of the $\Delta Z_{h}$ distributions for each match. (a) Raw CPOL data, (b) after the RCA, and (c) after RCA and $\Delta Z_{h}$ corrections. The $\Delta Z_{h}$ average is represented by the orange dashed lines and the weighted $\Delta Z_{h}$ average is represented by the green dashed line for the period from 7 Nov 2013 to the end of the season, that is, the period of reference for the RCA (cf. Fig. 4).

to $Z_{h}$ and $Z_{\mathrm{dr}}$ for consistency. We use the same criteria from Table 1 in Gourley et al. (2009) to CPOL polarimetric variables prior to estimating the selfconsistency relationship. In short, we rejected rays that have $Z_{h}>50 \mathrm{~dB} Z, Z_{\mathrm{dr}}>3.5 \mathrm{~dB}$, and $\phi_{\mathrm{dp}}>12^{\circ}$. We also looked only at the first $70 \mathrm{~km}$ of range, for rain only. The maximum diameter considered for the calculation of $Z_{h}$ is the default $9 \mathrm{~mm}$; however, we note that the maximum measured raindrop diameter is only $5.4 \mathrm{~mm}$.

Figure 11 shows the normalized density histogram of $K_{\mathrm{dp}} / Z_{h}$ versus $Z_{\mathrm{dr}}$ for CPOL in 2006 , that is, the same year as the disdrometer measurements used later for comparisons. The reflectivity in natural units $\left(\mathrm{mm}^{6} \mathrm{~m}^{-3}\right)$ is used here. The sample size is greater than 180 million data points. The black curve is a third-order polynomial fit to CPOL data: $f(x)=10^{-6} \times\left(-0.78 x^{3}+6.74 x^{2}-22.4 x+49.9\right)$,

where $x$ is $Z_{\mathrm{dr}}$. Data for $Z_{\mathrm{dr}}<0.5 \mathrm{~dB}$ or $Z_{\mathrm{dr}}>2.5 \mathrm{~dB}$ are much sparser and this does not allow an accurate fit of the self-consistency curve for CPOL. This is due to the criteria used to select regions with sufficiently large differential phase but not too large to avoid any potential effect from attenuation and differential attenuation. This curve is our reference for deriving the optimal set of assumptions using the T-matrix disdrometer calculations. For the sake of comparison, the Gourley et al. (2009) midlatitude relationship is shown. Large differences are found. This important result highlights the need to derive local self-consistent relationships to use this approach. If the Gourley et al. (2009) relationship were used to calibrate CPOL, then a 2-dB underestimation would result. 

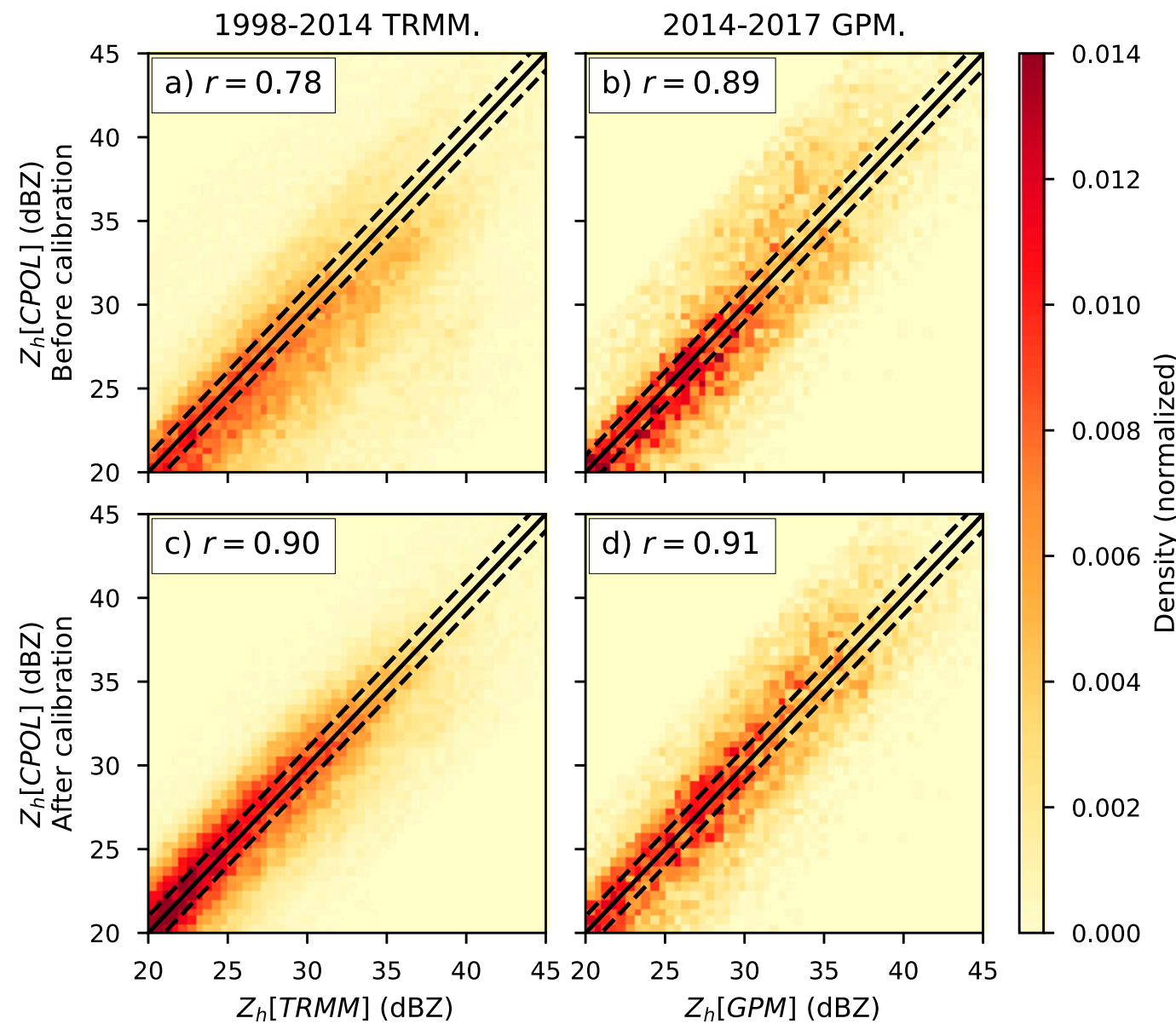

FIG. 10. Density plots of the comparison between CPOL reflectivity and (a),(c) TRMM, and (b),(d) GPM reflectivities for (a),(b) before and (c),(d) after calibration. The individual volume-matched samples are about 255000 for TRMM and 20000 for GPM. The dashed lines represent $\pm 1 \mathrm{~dB}$ from perfect correlation.

\section{b. Parameterization of the T-matrix formulation using disdrometer data}

The raindrop-shape model, the temperature, and the standard deviation of the canting angle $\operatorname{std}(C)$ of raindrops need to be assumed to derive polarimetric radar variables using T-matrix simulations from disdrometer observations. Observed counts from the disdrometer are used as input to the T-matrix simulations in this study. Yet these parameters can be difficult to ascertain and all depend on the local microphysics of rain. In the following, we compare results using three different temperatures $T=0^{\circ}, 10^{\circ}$, and $20^{\circ} \mathrm{C}$. Bringi et al. (2008) showed, using $2 \mathrm{D}$ video disdrometer, that in moderate wind conditions, the peak of the $\operatorname{std}(C)$ distribution is between $7^{\circ}$ and $12^{\circ}$ but with values that range from $4^{\circ}$ to $20^{\circ}$. Generally a value of $10^{\circ}$ is used in the literature for calibrating radars with the self-consistency (Bringi and Chandrasekar 2001). Because we want to study how $\operatorname{std}(C)$ impacts the self-consistency results, we consider all $\operatorname{std}(C)$ values ranging from $1^{\circ}$ to $30^{\circ}$ in $1^{\circ}$ increments.

Figure 12 shows the variation (\%) caused by temperature on the self-consistency curves. More precisely,

$$
V(X)=100 \times\left[X\left(20^{\circ} \mathrm{C}\right)-X\left(0^{\circ} \mathrm{C}\right)\right] / X\left(0^{\circ} \mathrm{C}\right),
$$

where $X$ is the self-consistency function for a given temperature. The temperature is responsible for the dispersion of self-consistency curves for high $Z_{\mathrm{dr}}$ values, but it does not have a significant impact for $0.5<Z_{\mathrm{dr}}<2 \mathrm{~dB}$, where the majority of the radar data lies. Thus, the temperature impact can be neglected, and $T=20^{\circ} \mathrm{C}$ is taken hereafter.

Figure 13 shows the T-matrix results for six different raindrop-shape models. The six representative raindropshape models shown in Fig. 13 are those often used in the literature (Beard and Chuang 1987; Brandes et al. 2002; Goddard et al. 1982; Pruppacher and Beard 1970; Thurai et al. 2007; Thurai and Bringi 2005). Note that the 


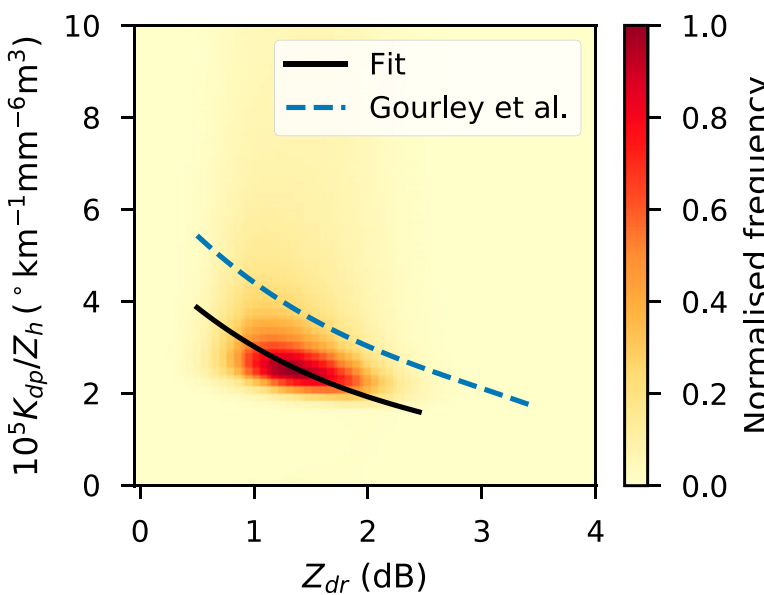

FIG. 11. Density plot of $K_{\mathrm{dp}} / Z_{h}$ vs $Z_{\mathrm{dr}}$ for CPOL in 2006. The sample size is $>180$ million. The solid black curve is a third-order polynomial fit. The dashed curve is the self-consistency relationship from Gourley et al. (2009).

Thurai et al. (2007) model is actually based on the Beard and Kubesh (1991) model. The scatterplots seen in Fig. 13 show the results given by the T-matrix for $T=$ $20^{\circ} \mathrm{C}$ and $\operatorname{std}(C)=5^{\circ}$. The different colored curves are third-order polynomial fits of the T-matrix results for the same temperature but for different $\operatorname{std}(C)$. For the sake of clarity, only $\operatorname{std}(C)=5^{\circ}, 10^{\circ}, 20^{\circ}$, and $30^{\circ}$, and $T=$ $20^{\circ} \mathrm{C}$ are shown. The plain black curve is the CPOL polynomial fit from Fig. 11. In Fig. 13, all raindrop-shape models show a high dispersion around their inflexion point, but the Pruppacher and Beard (1970) and Thurai and Bringi (2005) models seem to have an unrealistic behavior for $Z_{\mathrm{dr}}<0.5 \mathrm{~dB}$. The former model was already noted as a source of error in Gourley et al. (2009). Even though Thurai and Bringi (2005) claimed that their model was not very different from the Brandes et al. (2002) model, Fig. 13 shows that small differences in the model parameterization cause important variations in the T-matrix results. Based on these results, the Pruppacher and Beard (1970) and Thurai and Bringi (2005) raindropshape models are excluded from further analysis.

To find the best $\operatorname{std}(C)$ value for the T-matrix retrievals, we compute the root-mean-square (RMS) error of these retrievals against the self-consistency of CPOL data. Figure 14 shows the RMS error as a function of $\operatorname{std}(C)$ for the Beard and Chuang (1987), Brandes et al. (2002), Goddard et al. (1982), and Thurai et al. (2007) raindrop-shape models. The Brandes et al. (2002) raindrop-shape model shows the smallest RMS error of all distributions for $\operatorname{std}(C)=12^{\circ}$. The Thurai et al. (2007) and Beard and Chuang (1987) models also present small RMS errors, but for higher $\operatorname{std}(C), 15^{\circ}$ and $18^{\circ}$, respectively. However, these two models have a higher

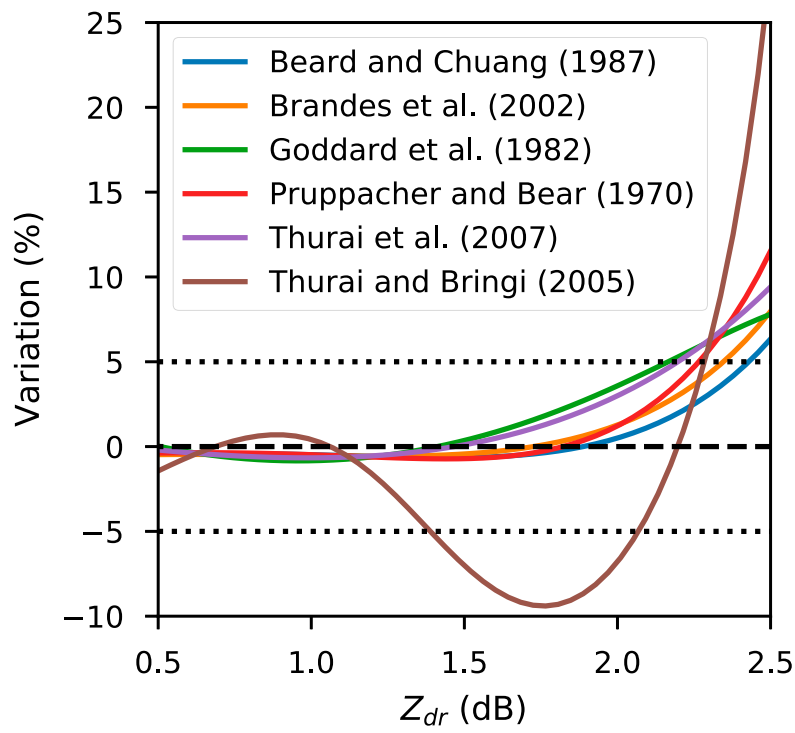

FIG. 12. Variation (\%) caused by the temperature in the selfconsistency relationships between $T=0^{\circ}$ and $20^{\circ} \mathrm{C}$ for the six different raindrop-shape models and for $\operatorname{std}(C)=10^{\circ}$.

bias than the Brandes et al. (2002) model. As for the Goddard et al. (1982) model, even though it has a higher RMS error than the other models, its minimal RMS error is around $10^{\circ}$ and it shows almost no variation for $\operatorname{std}(C) \leq 12^{\circ}$, while all the other models have a welldefined minimum and diverge quickly from it.

To assess how well the T-matrix simulations reproduce the CPOL polarimetric data, we compute the reflectivity that would be measured if the polarimetric variables $K_{\mathrm{dp}}$ and $Z_{\mathrm{dr}}$ follow the self-consistency curves shown in Fig. 13. This is shown in Fig. 15 for Brandes et al. (2002) (Fig. 15a), Thurai et al. (2007) (Fig. 15b), Goddard et al. (1982) (Fig. 15c), and Beard and Chuang (1987) (Fig. 15d) raindrop-shape models for $\operatorname{std}(C)=$ $12^{\circ}, 15^{\circ}, 18^{\circ}$, and $10^{\circ}$, respectively. This self-consistent $Z_{h}(\mathrm{dBZ})$ is defined as

$$
Z_{h}=10 \log _{10}\left[\frac{K_{\mathrm{dp}}}{f\left(Z_{\mathrm{dr}}\right)}\right],
$$

where $f$ is the fit of a given self-consistent curve. In Fig. 15 the self-consistent curve is as follows:

for Brandes et al. (2002) (Fig. 15a):

$$
f(x)=10^{-5} \times\left(-0.23 x^{3}+1.577 x^{2}-4.577 x+6.607\right),
$$

for Thurai et al. (2007) (Fig. 15b):

$$
f(x)=10^{-5} \times\left(-0.21 x^{3}+1.516 x^{2}-4.527 x+6.051\right),
$$



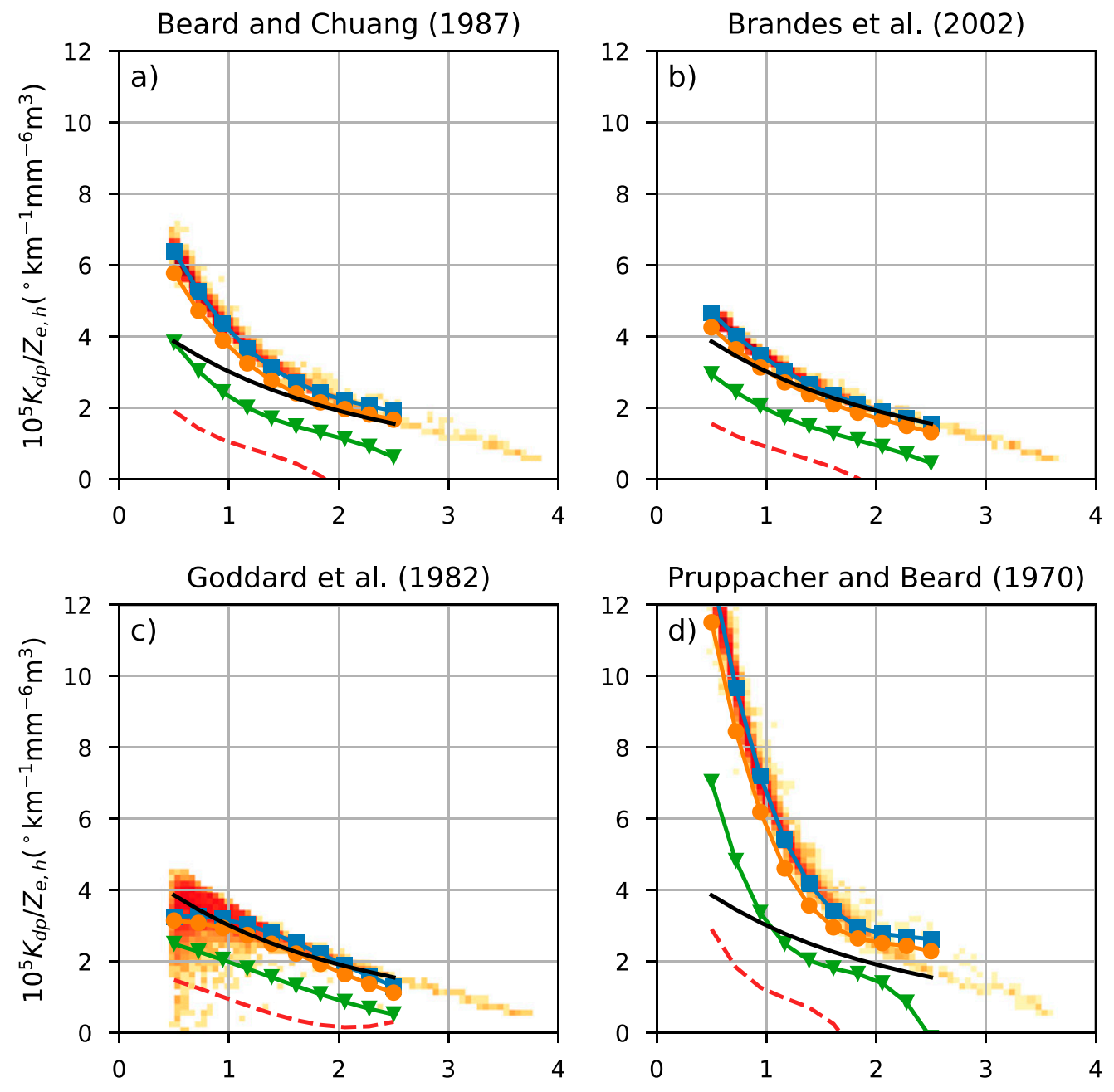

Thurai et al. (2007)
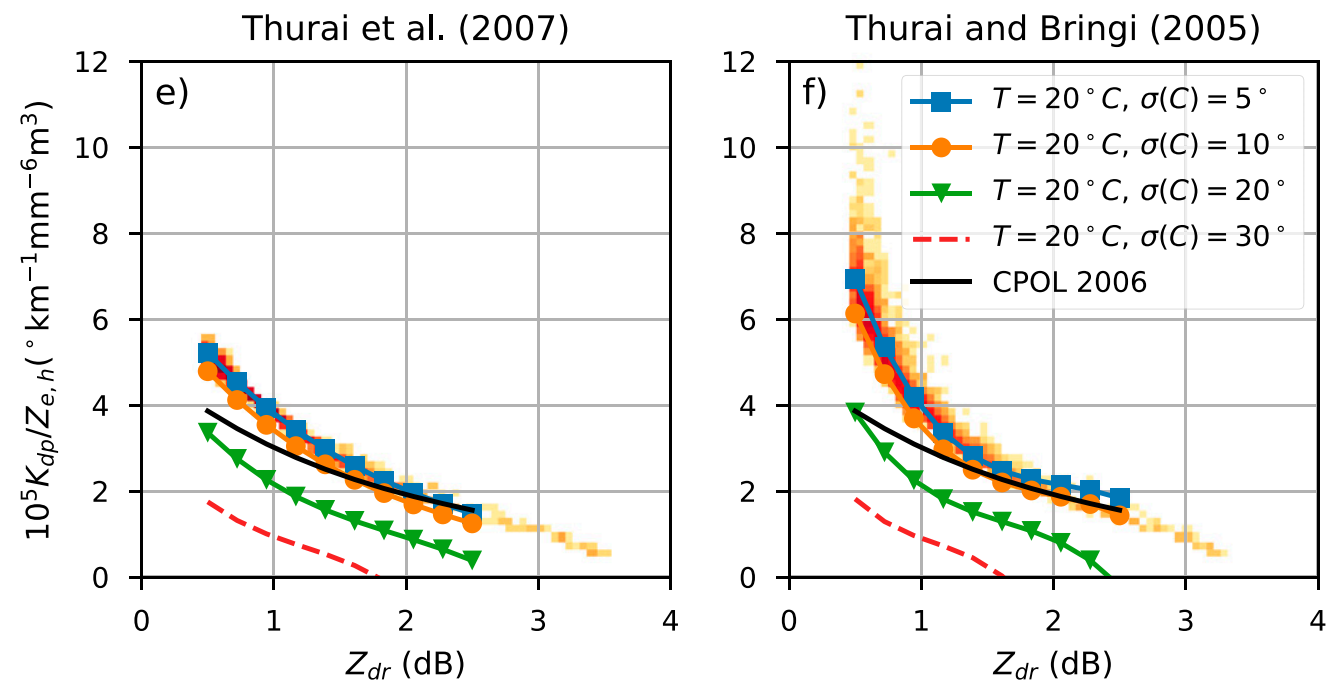

FIG. 13. Density plots of the T-matrix results at $T=0^{\circ} \mathrm{C}$ and $\operatorname{std}(C)=5^{\circ}$ for six different raindrop-shape models. The colored curves are the polynomial fits of the T-matrix results for $T=20^{\circ} \mathrm{C}$, and $\operatorname{std}(C)=5^{\circ}, 10^{\circ}, 20^{\circ}$, and $30^{\circ}$. The solid black curve is the fit of CPOL data from Fig. 11. The raindrop-shape models are (a) Beard and Chuang (1987), (b) Brandes et al. (2002), (c) Goddard et al. (1982), (d) Pruppacher and Beard (1970), (e) Thurai et al. (2007), and (f) Thurai and Bringi (2005). 


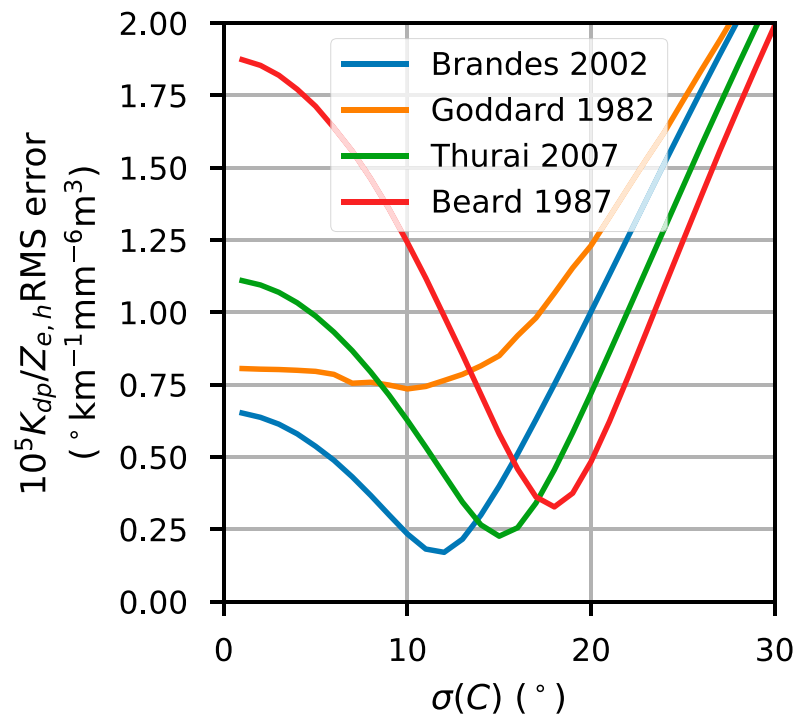

FIG. 14. RMS error of the T-matrix disdrometer data against the CPOL self-consistent relationship as a function of the standard deviation of the canting angle for the raindrop-shape models of Beard and Chuang (1987), Brandes et al. (2002), Goddard et al. (1982), and Thurai et al. (2007).

for Goddard et al. (1982) (Fig. 15c):

$$
f(x)=10^{-5} \times\left(-0.23 x^{3}+1.260 x^{2}-0.985 x+2.942\right),
$$

and for Beard and Chuang (1987) (Fig. 15d) raindropshape models:

$$
f(x)=10^{-5} \times\left(-0.57 x^{3}+3.369 x^{2}-7.327 x+7.139\right),
$$

where $x$ is $Z_{\mathrm{dr}}$, and $f$ is valid for $0.5<Z_{\mathrm{dr}}<3.5 \mathrm{~dB}$.

Figure 15 clearly shows that the reflectivity retrieved by means of the self-consistent curves and the reflectivity measured by CPOL are in very good agreement for $10<Z_{h}<30 \mathrm{~dB} Z$. Within this reflectivity range, the Brandes et al. (2002) (Fig. 15a) and the Goddard et al. (1982) (Fig. 15c) raindrop-shape models show correlation coefficients of 0.95 and 0.94 , respectively. We suspect that for $Z_{h}>30 \mathrm{~dB} Z$, departure from the 1:1 line is caused by $\mathrm{C}$-band attenuation, while for $Z_{h}<10 \mathrm{~dB} Z$, the differences probably come from the raindrop-shape model, where there is an important uncertainty for low $Z_{\mathrm{dr}}$ values (and thus lower $Z_{h}$ values). As for the Thurai et al. (2007) and Beard and Chuang (1987) raindrop-shape models, their lower correlation coefficients could be explained by Figs. 13a and $13 \mathrm{e}$, respectively, as these figures imply that $\operatorname{std}(C)$ is $Z_{\mathrm{dr}}$ dependent for the CPOL data curve. More precisely, for the CPOL curve on these models, $\operatorname{std}(C) \sim 20^{\circ}$ for $Z_{\mathrm{dr}}<1 \mathrm{~dB}$, while $\operatorname{std}(C)<10^{\circ}$ for $Z_{\mathrm{dr}}>2 \mathrm{~dB}$. Because the maximum of the CPOL data distribution is found for $1<Z_{\mathrm{dr}}<2 \mathrm{~dB}$, the Thurai et al. (2007) and Beard and Chuang (1987) models fit very well here but strongly diverge elsewhere.

In view of the results, we use in what follows the Brandes et al. (2002) raindrop-shape model for $T=20^{\circ} \mathrm{C}$ and $\operatorname{std}(C)=12^{\circ}$ as our best estimate for the T-matrix calculations. We have computed monthly values of the self-consistency of CPOL and found no remarkable differences within or between seasons. Even the period between 2002 and 2007, when the data resolution was changed, is similar to the other periods.

\section{c. Using the self-consistency curves to monitor $Z_{h}$}

Now that the T-matrix simulations have been tuned to match the reference CPOL self-consistent relationship, we assess in what follows the usability of this technique to monitor the reflectivity calibration. To do so, we artificially add an offset, ranging from -3 to $3 \mathrm{~dB}$, to the reflectivity computed by the T-matrix algorithm, represented by the dashed curves in Fig. 16, still for year 2006. We also added an offset to the reflectivity measured by CPOL, as shown in Fig. 16 for an offset of 3 (Fig. 16a), 0 (Fig. 16b), and $-3 \mathrm{~dB}$ (Fig. 16c). Figure 16 clearly shows that any change from the reference value of calibration is not only detected but also properly estimated by the self-consistent curves from the T-matrix computations. The curves in Fig. 16 can thus be used to estimate the offset needed to calibrate $Z_{h}$ with an accuracy better than $1 \mathrm{~dB}$.

\section{d. Using the self-consistency curves to monitor $Z_{\mathrm{dr}}$}

As discussed previously, the principle of the selfconsistency is that when two parameters out of $K_{\mathrm{dp}}$, $Z_{h}$, and $Z_{\mathrm{dr}}$ are known, the third one can be estimated. In the previous sections, we have used the self-consistency technique to calibrate $Z_{h}$ if $K_{\mathrm{dp}}$ and $Z_{\mathrm{dr}}$ are known and calibrated, respectively. When $Z_{h}$ and $K_{\mathrm{dp}}$ are known, then in principle the self-consistency approach can be used to calibrate $Z_{\mathrm{dr}}$. To illustrate the potential of monitoring the calibration of $Z_{\mathrm{dr}}$ using self-consistency principles, we use calibrated CPOL data from the season 2016/17. It must be noted that selecting other seasons led to the same results. We also used the birdbath technique for the same period to estimate a reference $Z_{\mathrm{dr}}$ calibration to compare with the self-consistency. The birdbath technique finds that the $Z_{\mathrm{dr}}$ bias is $1.2 \pm 0.2 \mathrm{~dB}$ for the entire 2016/17 season.

Figure 17a shows the self-consistency of the radar data for November 2016. The dotted lines represent the self-consistency curves, computed from disdrometer 

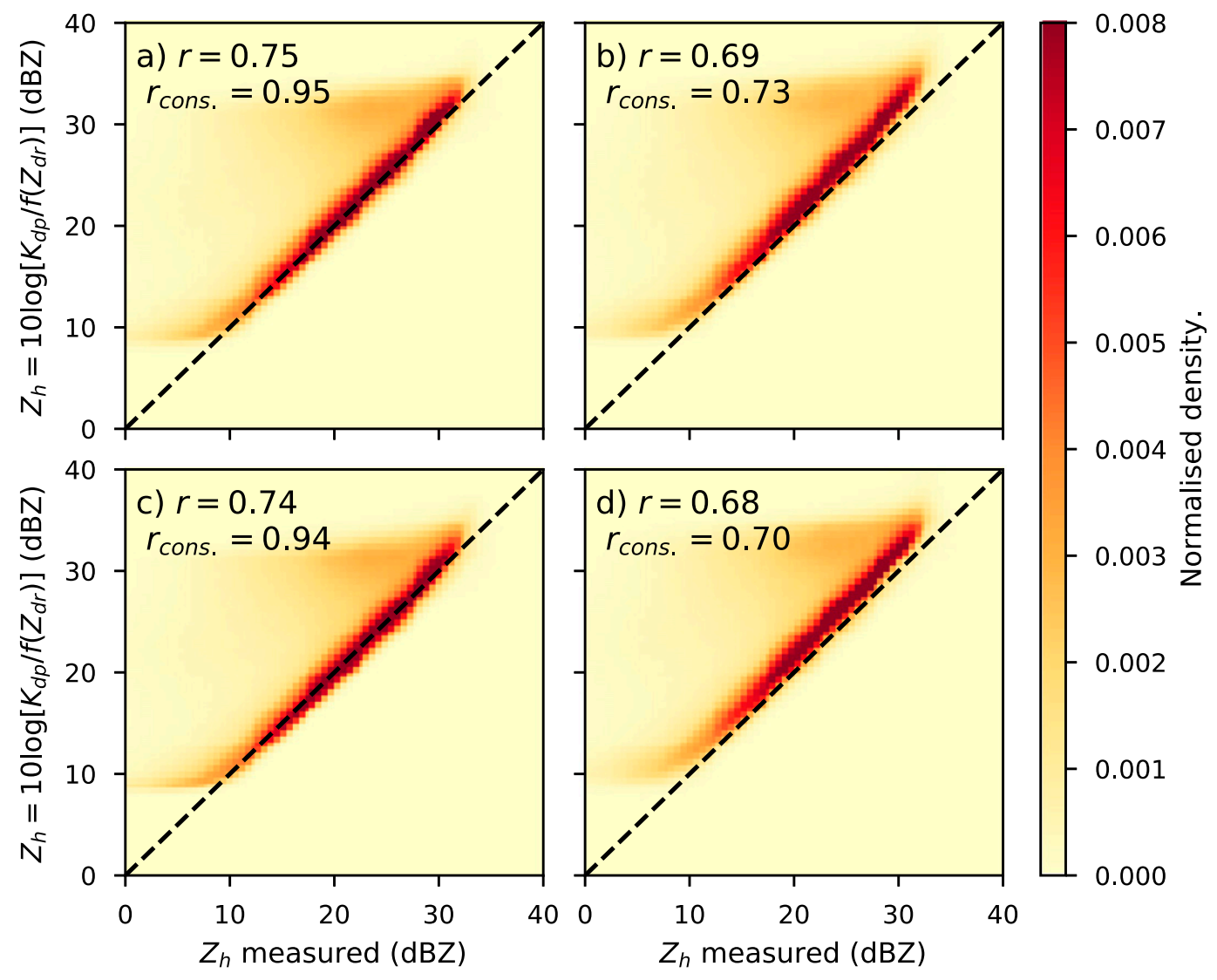

FIG. 15. Density plots of $Z_{h}$ measured by CPOL compared to $Z_{h}$ retrieved through the self-consistency relationship of $Z_{\mathrm{dr}}$ and $K_{\mathrm{dp}}$ for (a) Brandes et al. (2002), (b) Thurai et al. (2007), (c) Goddard et al. (1982), and (d) Beard and Chuang (1987) raindrop-shape models for $\operatorname{std}(C)=12^{\circ}$ and $15^{\circ}$, respectively; and at $T=20^{\circ} \mathrm{C}$. Term $r_{\text {cons }}$ is the Pearson coefficient for data between $10<Z_{h}<30 \mathrm{dBZ}$.

data, with an offset ranging from -.5 to $1.5 \mathrm{~dB}$, in increments of $0.5 \mathrm{~dB}$, added to $Z_{\mathrm{dr}}$. The $\sim 1.2$-dB offset on $Z_{\mathrm{dr}}$ detected by the birdbath calibration technique is clearly identifiable in Fig. 17a. As in Fig. 16 for the reflectivity, a set of various offset curves can be computed for $Z_{\mathrm{dr}}$ (Fig. 17a).

To quantitatively assess the potential of the selfconsistency technique to estimate the calibration offset of $Z_{\mathrm{dr}}$ to within the required accuracy of $0.1-0.2 \mathrm{~dB}$, we compute $\Delta Z_{\mathrm{dr}}=K_{\mathrm{dp}} / Z_{h}-f\left(Z_{\mathrm{dr}}\right)$, where $f\left(Z_{\mathrm{dr}}\right)$ is Eq. (9), that is, the distribution of differences between the selfconsistency relationship of CPOL data compared to the T-matrix disdrometer retrievals for November 2016 (Fig. 17b). The red line in Fig. 17b represents the $Z_{\mathrm{dr}}$ calibration value found using the birdbath technique. The $Z_{\mathrm{dr}}$ calibration offset found by the self-consistency technique is $1.2 \pm 0.2 \mathrm{~dB}$, that is, the exact same offset found by the birdbath technique. Thus, both techniques can be used successfully to monitor $Z_{\mathrm{dr}}$ calibration, provided that $Z_{h}$ is carefully calibrated before using the self-consistency technique. However, the amount of data required to calibrate $Z_{\mathrm{dr}}$ using the self-consistency technique is much larger than for the birdbath technique. In both cases we used 1 month of data (January 2017), but for the birdbath technique this amounts to only 15000 points compared to around 100 million for the selfconsistency. To assess how many data points are required to reach a calibration accuracy better than $0.2 \mathrm{~dB}$ with the self-consistency approach, we have applied the selfconsistency $Z_{\mathrm{dr}}$ calibration technique daily, then in groups of increasingly more days within the test month of January 2017, up to 1 week. Our results indicate that when using 1 day, the self-consistency technique cannot calibrate $Z_{\mathrm{dr}}$ to better than about $0.5 \mathrm{~dB}$, while in contrast the right offset of -1.2 could be retrieved when using 5 days or more of rainy data. Repeating the same procedure to other months of data yielded the same conclusions. Therefore, in conclusion, although when possible the birdbath technique should obviously be the preferred technique for $Z_{\mathrm{dr}}$ calibration, the self-consistency approach can be applied to chunks of 5 days or more of rainy periods to calibrate $Z_{\mathrm{dr}}$ to an accuracy better than $0.2 \mathrm{~dB}$. 

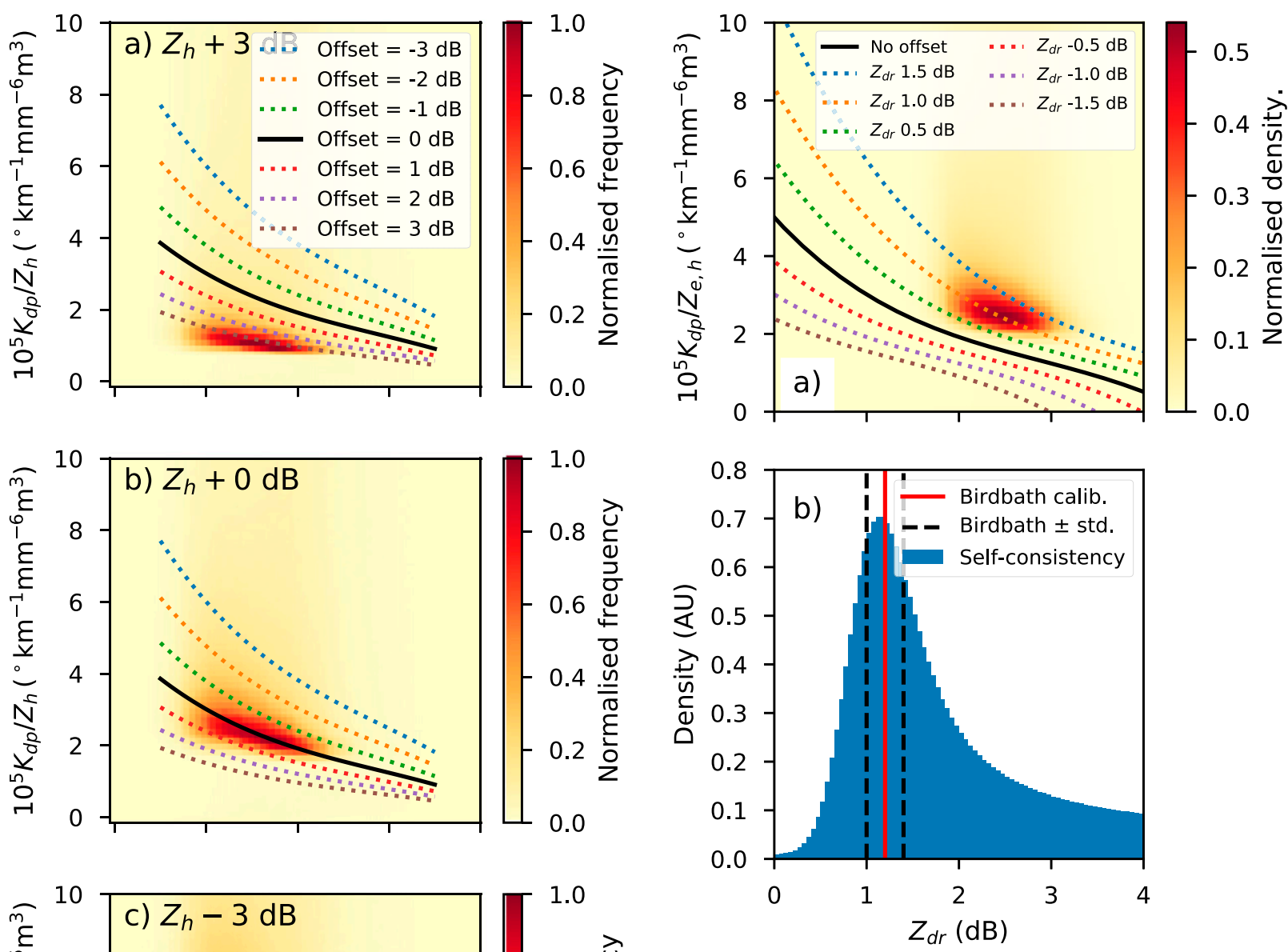

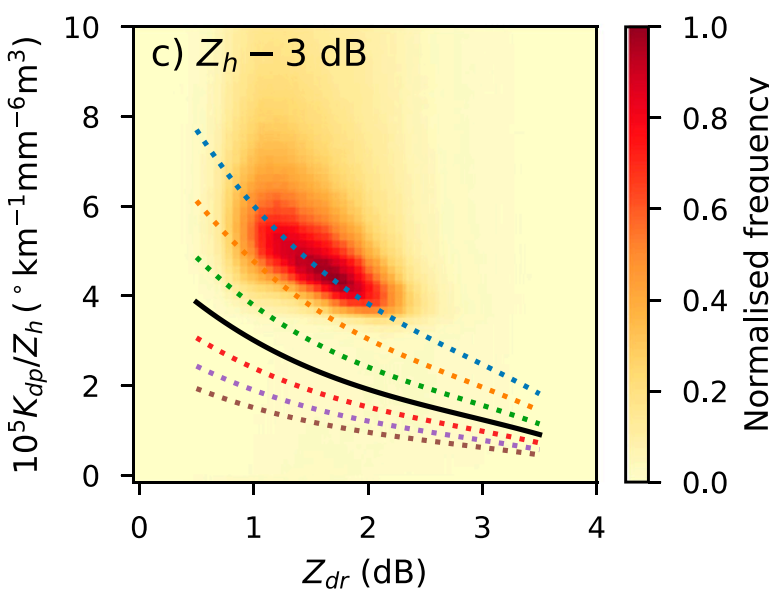

FIG. 16. Density plots of the self-consistency of the calibrated radar data for November 2016 when offsets of (a) 3, (b) 0, and (c) $-3 \mathrm{~dB}$ are added to $Z_{h}$. The solid black line is the self-consistency result from the disdrometer data using the T-matrix algorithm for the Brandes et al. (2002) raindrop-shape model with $T=20^{\circ} \mathrm{C}$ and $\operatorname{std}(C)=12^{\circ}$. The dotted lines are the curves of self-consistency, with an offset ranging from -3 to $3 \mathrm{~dB}$, in increments of $1 \mathrm{~dB}$, added to $Z_{h}$.

\section{e. Calibration using scattering simulations of $Z_{h}$ with permanent disdrometer observations}

With the self-consistency technique, we use measurements from a disdrometer to find the parameterization that
FIG. 17. (a) Histogram of the self-consistency of the radar data for November 2016, where $Z_{h}$ is calibrated but not $Z_{\mathrm{dr}}$. The dotted curves represent the curve of self-consistency with an offset added to $Z_{\mathrm{dr}}$. The solid black curve is the self-consistency result from the disdrometer data using the T-matrix algorithm for Brandes et al. (2002) raindrop-shape model at $T=20^{\circ} \mathrm{C}$ and $\operatorname{std}(C)=12^{\circ}$ (solid black curve). (b) Histogram of the variation of the self-consistency of CPOL data for November 2016 minus the relationship from T-matrix disdrometer retrievals for Brandes et al. (2002) raindropshape model with $T=20^{\circ} \mathrm{C}$ and $\operatorname{std}(C)=12^{\circ}$. The red line is the calibration value for $Z_{\mathrm{dr}}$ found using the birdbath technique.

best fits our calibrated radar. Once the self-consistency is correctly parameterized, the disdrometer is not needed anymore, as the radar reflectivity is then compared to the self-consistent curve.

The more conservative way to calibrate radar with the disdrometer is to compare radar reflectivity with scattering simulations of the reflectivity from the disdrometer (e.g., Stout and Mueller 1968). The fundamental problems with comparing reflectivities from the surface disdrometer and the scanning radar are as follows: 1 ) the radar senses well above the surface and the drop size distribution (i.e., reflectivity) can evolve as precipitation falls to the surface, and 2) these instruments have different spatial 

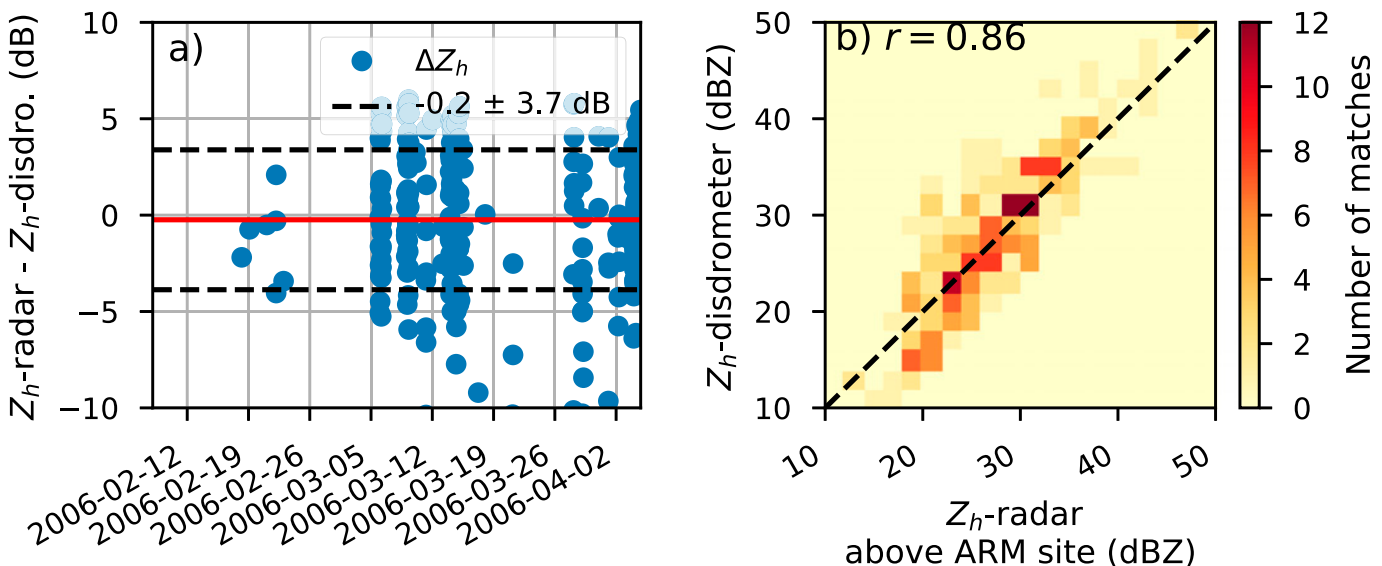

FIG. 18. (a) Time series of the difference between the radar reflectivity above the disdrometer site and the simulated disdrometer reflectivity averaged to the same time frequency as the radar ( $10 \mathrm{~min})$ for 2006 . The solid red line represents $\overline{\Delta Z_{h}}=-0.2 \mathrm{~dB}$. The time series average and standard deviation are $-0.2 \pm 3.7 \mathrm{~dB}$. (b) Histogram of the radar reflectivity above the disdrometer site compared to the reflectivity retrieved from the disdrometer measurements. There are 284 points of comparison from February to April 2006.

(the disdrometer is just one point) and temporal resolutions (about $1 \mathrm{~min}$ for the disdrometer). This would not be a problem if the precipitation was not varying in time and space. But since precipitation is variable at different temporal and spatial resolutions, the uncertainties from each instrument will be a combination of the instrument measurement error and the spatiotemporal variability of the precipitation (Williams et al. 2005).

Figure 18a shows the time series of the comparison between CPOL reflectivity and the disdrometer reflectivity, and Fig. 18b shows a histogram comparing the reflectivity between the two instruments. The disdrometer data have been resampled to the same frequency as the radar data $(10 \mathrm{~min})$. In total, there are 299 matches between the disdrometer and the radar. We removed disdrometer samples with a standard deviation above $10 \mathrm{~dB}$, leaving 284 matches for comparison. The reflectivity of the pixel directly above the disdrometer site and its direct adjacent neighbors (eight of them) are averaged for comparison with the disdrometer. We used the reflectivity calibrated by the RCA and the comparison with TRMM as input. Figure 18 shows that the mean difference between CPOL and the disdrometer is around $0.2 \mathrm{~dB}$, but the standard deviation is around $3.7 \mathrm{~dB}$. Figure $18 \mathrm{~b}$ also shows a good correlation between the two instruments $(r=0.86)$ but with large variability. This implies a similar conclusion as in Williams et al. (2005) and Frech et al. (2017), that although there is large variability between matched observations, the comparisons with the disdrometer are still meaningful. However, it appears clearly that uncertainties associated with this simple disdrometer calibration are much larger than what can be achieved with the combination of RCA and satellite comparisons. This simpler approach should therefore be used only in regions or time periods without TRMM or GPM coverage.

\section{Integrated approach calibration framework}

The RCA and the volume-matching technique are the elements that we introduced for our integrated approach SCAR to adjust the calibration of reflectivity. The self-consistency and birdbath techniques are all part of a broader framework for calibrating the differential reflectivity, as illustrated in Fig. 19.

To calibrate $Z_{h}$, first the RCA is used, as it allows us to correct with great accuracy day-to-day variations of the radar calibration toward a predefined baseline. Then, the preferred way is to use the volume-matching technique to determine the absolute value of calibration of the RCA baseline. This is the SCAR framework. If satellite data are not available, then we use the selfconsistency technique. Note that in this case, $Z_{\mathrm{dr}}$ must already be calibrated, for example, using the birdbath technique.

The preferred way to calibrate $Z_{\mathrm{dr}}$ is to use the birdbath technique. If vertically pointing scans are not available, then the self-consistency technique can be used, provided that $Z_{h}$ is calibrated. We propose using reflectivity comparison with a disdrometer as a last resort, since 1) it requires a disdrometer to be always present and (2) this technique has the highest uncertainty of all techniques considered here.

The reasons the volume-matching technique is the preferred way for our integrated approach are as 


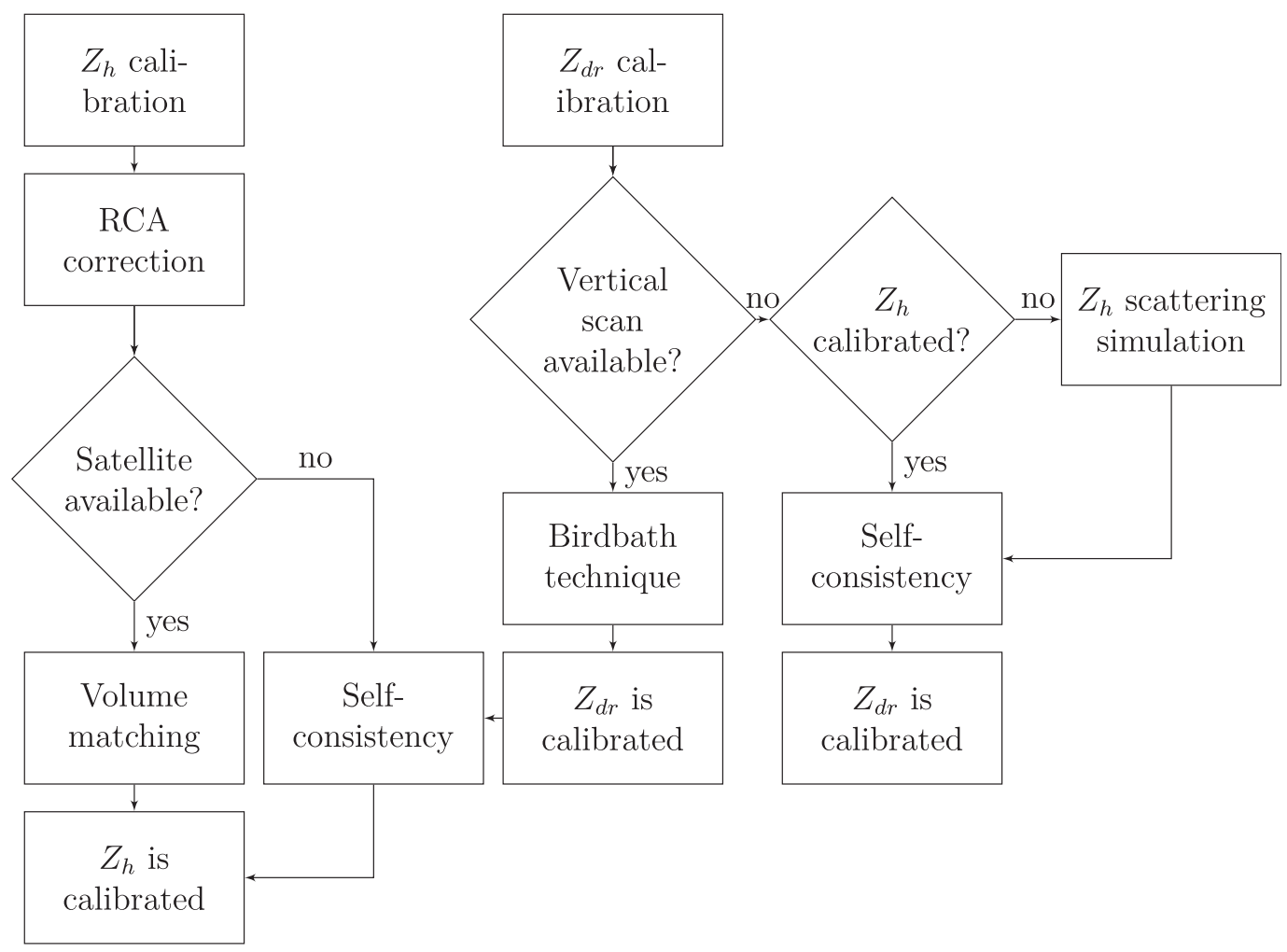

FIG. 19. Framework for adjusting the calibration of radar reflectivity and differential reflectivity.

follows: 1) it works for single-polarization radar too and (2) the self-consistency relationship changes from radar to radar and therefore must be tuned using dedicated disdrometer observations.

The RCA technique is already in use at the Australia Bureau of Meteorology (BoM) for automatic monitoring of the calibration of 13 weather radars of the operational network (those recording uncorrected reflectivities). The SCAR integrated approach is also currently being ported at BoM for automatic comparison of the entire Australian radar network with GPM. At the time of writing, the Australian weather radar network is in the process of being upgraded to dual polarization. Plans to put disdrometers at some radar sites, which could allow the use of the self-consistency technique, are also in discussion.

\section{Discussion and summary}

In this paper an integrated approach for ground radar calibration, named SCAR, has been developed and tested using 17 years of tropical radar observations collected by the Darwin CPOL. The SCAR approach makes use of an improved version of the RCA technique to track calibration changes and a modified version of the satellite volume-matching technique from Warren et al. (2018) to derive the absolute calibration. We demonstrate that using this integrated approach, the absolute calibration can be achieved to within $1 \mathrm{~dB}$ and monitored to an accuracy better than $0.5 \mathrm{~dB}$.

Using 17 years of CPOL-calibrated dual-polarization data and disdrometer observations, we have then studied the self-consistent calibration technique for this tropical location. We found that the CPOL-derived self-consistent relationship was very different from the midlatitude relationship derived at $\mathrm{C}$ band by Gourley et al. (2009). This important result highlights the fact that caution should be exercised before using relationships from the literature to observations from different geographical locations. Our recommendation is to use local disdrometer observations, combined with our integrated SCAR approach, to achieve an accurate calibration. The second important result is that the T-matrix estimates of the self-consistent relationship are very sensitive to the assumed standard deviation of the canting angle and drop-shape model. We found that only a few of the proposed drop-shape models and the standard deviation of the canting angle in the literature could reasonably reproduce our CPOL self-consistent relationship. The combination of the Brandes et al. (2002) drop-shape model and a standard deviation angle of $12^{\circ}$ was found to provide the best match to the CPOL calibrated data, 
with the Goddard et al. (1982) drop-shape model and a $10^{\circ}$ standard deviation of canting angle a reasonably good match too. Finally, we also showed that the selfconsistent relationships can be used to estimate the calibration of $Z_{\mathrm{dr}}$ to within about $0.2 \mathrm{~dB}$, an accuracy similar to that obtained with the traditional birdbath technique, provided that $Z_{h}$ is calibrated and $K_{\mathrm{dp}}$ is known. This result is particularly interesting for radars that cannot perform vertical scans, such as the U.S. WSR-88D of the NEXRAD network. For these radars the selfconsistency technique should be used to monitor $Z_{\mathrm{dr}}$, while the SCAR approach could be used to monitor $Z_{h}$.

Acknowledgments. This work has been supported by the U.S. Department of Energy's Atmospheric System Research program through Grant DE-SC0014063. The contribution of Scott Collis through Argonne National Laboratory was supported by the U.S. Department of Energy, Office of Science, Office of Biological and Environmental Research, under Contract DE-AC0206CH11357. This work was partly supported by the Climate Model Development and Validation activity of the Department of Energy, Office of Science, Office of Biological and Environmental Research. We acknowledge the contributions of Brad Atkinson, Ray Jones, and Michael Whimpey in supporting the Darwin observatory and data management. We also want to thank the authors of the ARM Py-ART library for its usefulness in manipulating and processing radar data.

\section{REFERENCES}

Anagnostou, E. N., C. A. Morales, and T. Dinku, 2001: The use of TRMM precipitation radar observations in determining ground radar calibration biases. J. Atmos. Oceanic Technol., 18, 616-628, https://doi.org/10.1175/1520-0426(2001)018<0616: TUOTPR $>2.0 . \mathrm{CO} ; 2$.

Atlas, D., and S. C. Mossop, 1960: Calibration of a weather radar by using a standard target. Bull. Amer. Meteor. Soc., 41, 377-382, https://doi.org/10.1175/1520-0477-41.7.377.

Awaka, J., T. Iguchi, and K. Okamoto, 2009: TRMM PR standard algorithm 2A23 and its performance on bright band detection. J. Meteor. Soc. Japan, 87A, 31-52, https://doi.org/10.2151/ jmsj.87A.31.

Beard, K. V., and C. Chuang, 1987: A new model for the equilibrium shape of raindrops. J. Atmos. Sci., 44, 1509-1524, https://doi.org/10.1175/1520-0469(1987)044<1509:ANMFTE> 2.0.CO;2.

__ and R. J. Kubesh, 1991: Laboratory measurements of small raindrop distortion. Part II: Oscillation frequencies and modes. J. Atmos. Sci., 48, 2245-2264, https://doi.org/10.1175/ 1520-0469(1991)048<2245:LMOSRD > 2.0.CO;2.

Brandes, E. A., G. Zhang, and J. Vivekanandan, 2002: Experiments in rainfall estimation with a polarimetric radar in a subtropical environment. J. Appl. Meteor., 41, 674-685, https://doi.org/10.1175/1520-0450(2002)041<0674:EIREWA> 2.0.CO;2.
Bringi, V. N., and V. Chandrasekar, 2001: Polarimetric Doppler Weather Radar: Principles and Applications. Cambridge University Press, 636 pp., https://doi.org/10.1017/CBO9780511541094.

— T. A. Seliga, and S. M. Cherry, 1983: Statistical properties of the dual-polarization differential reflectivity (ZDR) radar signal. IEEE Trans. Geosci. Remote Sens., GE-21, 215-220, https://doi.org/10.1109/TGRS.1983.350491.

—_, V. Chandrasekar, N. Balakrishnan, and D. S. Zrnić, 1990: An examination of propagation effects in rainfall on radar measurements at microwave frequencies. J. Atmos. Oceanic Technol., 7, 829-840, https://doi.org/10.1175/1520-0426(1990) 007<0829:AEOPEI >2.0.CO;2.

- M. Thurai, and D. Brunkow, 2008: Measurements and inferences of raindrop canting angles. Electron. Lett., 44, 1425, https://doi.org/10.1049/el:20082899.

Cao, Q., Y. Hong, Y. Qi, Y. Wen, J. Zhang, J. J. Gourley, and L. Liao, 2013: Empirical conversion of the vertical profile of reflectivity from Ku-band to S-band frequency. J. Geophys. Res. Space Phys., 118, 1814-1825, https://doi.org/10.1002/ jgra.50246.

Chandrasekar, V., L. Baldini, N. Bharadwaj, and P. L. Smith, 2015: Calibration procedures for global precipitation-measurement ground-validation radars. URSI Radio Sci. Bull., 2015 (355), 45-73, https://doi.org/10.23919/URSIRSB.2015.7909473.

Frech, M., M. Hagen, and T. Mammen, 2017: Monitoring the absolute calibration of a polarimetric weather radar. J. Atmos. Oceanic Technol., 34, 599-615, https://doi.org/ 10.1175/JTECH-D-16-0076.1.

Giangrande, S. E., R. McGraw, and L. Lei, 2013: An application of linear programming to polarimetric radar differential phase processing. J. Atmos. Oceanic Technol., 30, 1716-1729, https:// doi.org/10.1175/JTECH-D-12-00147.1.

Goddard, J. W. F., S. M. Cherry, and V. N. Bringi, 1982: Comparison of dual-polarization radar measurements of rain with ground-based disdrometer measurements. J. Appl. Meteor., 21, 252-256, https://doi.org/10.1175/1520-0450(1982)021<0252: CODPRM $>2.0 . \mathrm{CO} ; 2$.

_ _ J. Tan, and M. Thurai, 1994: Technique for calibration of meteorological radars using differential phase. Electron. Lett., 30, 166-167, https://doi.org/10.1049/el:19940119.

Gorgucci, E., G. Scarchilli, and V. Chandrasekar, 1992: Calibration of radars using polarimetric techniques. IEEE Trans. Geosci. Remote Sens., 30, 853-858, https://doi.org/10.1109/36.175319.

,-- , and -1999 : A procedure to calibrate multiparameter weather radar using properties of the rain medium. IEEE Trans. Geosci. Remote Sens., 37, 269-276, https://doi.org/10.1109/ 36.739161.

, L. Baldini, and V. Chandrasekar, 2006: What is the shape of a raindrop? An answer from radar measurements. J. Atmos. Sci., 63, 3033-3044, https://doi.org/10.1175/JAS3781.1.

Gourley, J. J., A. J. Illingworth, and P. Tabary, 2009: Absolute calibration of radar reflectivity using redundancy of the polarization observations and implied constraints on drop shapes. J. Atmos. Oceanic Technol., 26, 689-703, https://doi.org/10.1175/ 2008JTECHA1152.1.

Gu, J. Y., A. Ryzhkov, P. Zhang, P. Neilley, M. Knight, B. Wolf, and D. I. Lee, 2011: Polarimetric attenuation correction in heavy rain at C band. J. Appl. Meteor. Climatol., 50, 39-58, https://doi.org/10.1175/2010JAMC2258.1.

Helmus, J. J., and S. M. Collis, 2016: The Python ARM Radar Toolkit (Py-ART), a library for working with weather radar data in the Python programming language. J. Open Res. Software, 4, e25, https://doi.org/10.5334/jors.119. 
Heymsfield, G. M., B. Geerts, and L. Tian, 2000: TRMM precipitation radar reflectivity profiles as compared with highresolution airborne and ground-based radar measurements. J. Appl. Meteor., 39, 2080-2102, https://doi.org/10.1175/ 1520-0450(2001)040<2080:TPRRPA > 2.0.CO;2.

Hitschfeld, W., and J. Bordan, 1954: Errors inherent in the radar measurement of rainfall at attenuating wavelengths. J. Meteor., 11, 58-67, https://doi.org/10.1175/1520-0469(1954) $011<0058$ :EIITRM $>2.0 . \mathrm{CO} ; 2$.

Hou, A. Y., and Coauthors, 2014: The Global Precipitation Measurement mission. Bull. Amer. Meteor. Soc., 95, 701-722, https://doi.org/10.1175/BAMS-D-13-00164.1.

Jorgensen, D. P., and P. T. Willis, 1982: A $Z-R$ relationship for hurricanes. J. Appl. Meteor., 21, 356-366, https://doi.org/ 10.1175/1520-0450(1982)021<0356:AZRRFH>2.0.CO;2.

Keenan, T., K. Glasson, F. Cummings, T. S. Bird, J. Keeler, and J. Lutz, 1998: The BMRC/NCAR C-band polarimetric (C-POL) radar system. J. Atmos. Oceanic Technol., 15, 871-886, https://doi.org/10.1175/1520-0426(1998)015<0871:TBNCBP> 2.0.CO;2.

_ - and Coauthors, 2003: The Sydney 2000 World Weather Research Programme Forecast Demonstration Project: Overview and current status. Bull. Amer. Meteor. Soc., 84, 1041-1054, https://doi.org/10.1175/BAMS-84-8-1041.

Kummerow, C., W. Barnes, T. Kozu, J. Shiue, and J. Simpson, 1998: The Tropical Rainfall Measuring Mission (TRMM) sensor package. J. Atmos. Oceanic Technol., 15, 809-817, https:// doi.org/10.1175/1520-0426(1998)015<0809:TTRMMT>2.0.CO;2.

Leinonen, J., 2014: High-level interface to $T$-matrix scattering calculations: Architecture, capabilities and limitations. Opt. Express, 22, 1655, https://doi.org/10.1364/OE.22.001655.

Liao, L., and R. Meneghini, 2009: Validation of TRMM precipitation radar through comparison of its multiyear measurements with ground-based radar. J. Appl. Meteor. Climatol., 48, 804-817, https://doi.org/10.1175/2008JAMC1974.1.

,$- \ldots$, and T. Iguchi, 2001: Comparisons of rain rate and reflectivity factor derived from the TRMM precipitation radar and the WSR88D over the Melbourne, Florida, site. J. Atmos. Oceanic Technol., 18, 1959-1974, https://doi.org/10.1175/1520-0426(2001)018<1959: CORRAR $>2.0 . \mathrm{CO} ; 2$.

Marks, D. A., D. B. Wolff, D. S. Silberstein, A. Tokay, J. L. Pippitt, and J. Wang, 2009: Availability of high-quality TRMM ground validation data from Kwajalein, RMI: A practical application of the relative calibration adjustment technique. J. Atmos. Oceanic Technol., 26, 413-429, https://doi.org/ 10.1175/2008JTECHA1174.1.

,,-- L. D. Carey, and A. Tokay, 2011: Quality control and calibration of the dual-polarization radar at Kwajalein, RMI. J. Atmos. Oceanic Technol., 28, 181-196, https://doi.org/ 10.1175/2010JTECHA1462.1.

Melnikov, V., and D. S. Zrnić, 2015: Feasibility of monitoring $\mathrm{Z}_{\mathrm{DR}}$ calibration using ground clutter. University of Oklahoma Tech. Rep. NPI-2015, 35 pp.

Meneghini, R., T. Iguchi, T. Kozu, L. Liao, K. Okamoto, J. A. Jones, and J. Kwiatkowski, 2000: Use of the surface reference technique for path attenuation estimates from the TRMM precipitation radar. J. Appl. Meteor., 39, 2053-2070, https://doi.org/10.1175/1520-0450(2001)040<2053:UOTSRT> 2.0.CO;2.

, J. A. Jones, T. Iguchi, K. Okamoto, and J. Kwiatkowski, 2004: A hybrid surface reference technique and its application to the TRMM precipitation radar. J. Atmos. Oceanic Technol., 21, 1645-1658, https://doi.org/10.1175/JTECH1664.1.
Mishchenko, M. I., L. D. Travis, and D. W. Mackowski, 1996: $T$-matrix computations of light scattering by nonspherical particles: A review. J. Quant. Spectrosc. Radiat. Transfer, 55, 535-575, https://doi.org/10.1016/0022-4073(96)00002-7.

Mueller, E. A., 1977: Statistics of high radar reflectivity gradients. J. Appl. Meteor., 16, 511-513, https://doi.org/10.1175/1520-0450(1977) $016<0511$ :SOHRRG $>2.0 . \mathrm{CO} ; 2$.

Park, S., S.-H. Jung, and G. Lee, 2015: Cross validation of TRMM PR reflectivity profiles using 3D reflectivity composite from the ground-based radar network over the Korean Peninsula. J. Hydrometeor., 16, 668-687, https://doi.org/10.1175/JHM-D14-0092.1.

Probert-Jones, J. R., 1962: The radar equation in meteorology. Quart. J. Roy. Meteor. Soc., 88, 485-495, https://doi.org/ 10.1002/qj.49708837810.

Protat, A., D. Bouniol, E. J. O'Connor, H. Klein Baltink, J. Verlinde, and K. Widener, 2011: CloudSat as a global radar calibrator. J. Atmos. Oceanic Technol., 28, 445-452, https:// doi.org/10.1175/2010JTECHA1443.1.

Pruppacher, H. R., and K. V. Beard, 1970: A wind tunnel investigation of the internal circulation and shape of water drops falling at terminal velocity in air. Quart. J. Roy. Meteor. Soc., 96, 247-256, https://doi.org/10.1002/qj.49709640807.

Rinehart, R. E., 1978: On the use of ground return targets for radar reflectivity factor calibration checks. J. Appl. Meteor., 17, 1342-1350, https://doi.org/10.1175/1520-0450(1978)017<1342: OTUOGR $>2.0 . \mathrm{CO} ; 2$.

Scarchilli, G., E. Gorgucci, V. Chandrasekar, and A. Dobaie, 1996: Self-consistency of polarization diversity measurement of rainfall. IEEE Trans. Geosci. Remote Sens., 34, 22-26, https:// doi.org/10.1109/36.481887.

Schumacher, C., and R. A. Houze, 2000: Comparison of radar data from the TRMM satellite and Kwajalein oceanic validation site. J. Appl. Meteor., 39, 2151-2164, https://doi.org/10.1175/ 1520-0450(2001)040<2151:CORDFT >2.0.CO;2.

Schwaller, M. R., and R. K. Morris, 2011: A ground validation network for the Global Precipitation Measurement mission. J. Atmos. Oceanic Technol., 28, 301-319, https://doi.org/ 10.1175/2010JTECHA1403.1.

Silberstein, D. S., D. B. Wolff, D. A. Marks, D. Atlas, and J. L. Pippitt, 2008: Ground clutter as a monitor of radar stability at Kwajalein, RMI. J. Atmos. Oceanic Technol., 25, 2037-2045, https://doi.org/10.1175/2008JTECHA1063.1.

Stout, G. E., and E. A. Mueller, 1968: Survey of relationships between rainfall rate and radar reflectivity in the measurement of precipitation. J. Appl. Meteor., 7, 465-474, https://doi.org/ 10.1175/1520-0450(1968)007<0465:SORBRR > 2.0.CO;2.

Thurai, M., and V. N. Bringi, 2005: Drop axis ratios from a 2D video disdrometer. J. Atmos. Oceanic Technol., 22, 966-978, https://doi.org/10.1175/JTECH1767.1.

_ G. J. Huang, V. N. Bringi, W. L. Randeu, and M. Schönhuber, 2007: Drop shapes, model comparisons, and calculations of polarimetric radar parameters in rain. J. Atmos. Oceanic Technol., 24, 1019-1032, https://doi.org/10.1175/JTECH2051.1.

Toyoshima, K., H. Masunaga, and F. A. Furuzawa, 2015: Early evaluation of Ku- and Ka-band sensitivities for the Global Precipitation Measurement (GPM) Dual-frequency Precipitation Radar (DPR). SOLA, 11, 14-17, https://doi.org/10.2151/sola.2015-004.

Vaccarono, M., R. Bechini, C. V. Chandrasekar, R. Cremonini, and C. Cassardo, 2016: An integrated approach to monitoring the calibration stability of operational dual-polarization radars. Atmos. Meas. Tech., 9, 5367-5383, https://doi.org/10.5194/ amt-9-5367-2016. 
Vivekanandan, J., G. Zhang, S. M. Ellis, D. Rajopadhyaya, and S. K. Avery, 2003: Radar reflectivity calibration using differential propagation phase measurement. Radio Sci., 38 (3), https://doi.org/10.1029/2002RS002676.

Vukovic, Z. R., J. M. C. Young, and N. Donaldson, 2014: Interradar comparison accounting for partially overlapping volumes. Proc. Eighth European Conf. on Radar in Meteorology and Hydrology, Garmisch-Partenkirchen, Germany, DWD and DLR, 7 pp., http://www.pa.op.dlr.de/erad2014/programme/ ExtendedAbstracts/046_Vukovic.pdf.

Wang, J., and D. B. Wolff, 2009: Comparisons of reflectivities from the TRMM precipitation radar and ground-based radars. J. Atmos. Oceanic Technol., 26, 857-875, https://doi.org/ 10.1175/2008JTECHA1175.1.

Warren, R. A., A. Protat, S. T. Siems, H. A. Ramsay, V. Louf, M. J. Manton, and T. A. Kane, 2018: Calibrating ground-based radars against TRMM and GPM. J. Atmos. Oceanic Technol., 35, 323-346, https://doi.org/10.1175/JTECH-D-17-0128.1.

Whiton, R. C., P. L. Smith Jr., and A. C. Harbuck, 1976: Calibration of weather radar systems using the sun as a radio source. 17th Conf. on Radar Meteorology, Seattle, WA, Amer. Meteor. Soc., 60-65.

Williams, C. R., K. S. Gage, W. Clark, and P. Kucera, 2005: Monitoring the reflectivity calibration of a scanning radar using a profiling radar and a disdrometer. J. Atmos. Oceanic Technol., 22, 1004-1018, https://doi.org/10.1175/ JTECH1759.1.

Wolff, D. B., D. A. Marks, and W. A. Petersen, 2015: General application of the relative calibration adjustment (RCA) technique for monitoring and correcting radar reflectivity calibration. J. Atmos. Oceanic Technol., 32, 496-506, https:// doi.org/10.1175/JTECH-D-13-00185.1. 